\title{
GOALS MATTER: AMPLIFICATION OF THE MOTIVATIONAL SIGNIFICANCE OF THE FEEDBACK WHEN GOAL IMPACT IS INCREASED
}

\author{
Severo, Mario Carlo ${ }^{1}$, Walentowska, Wioleta ${ }^{1,2}$, Moors, Agnes ${ }^{1,3}$, \& Pourtois, Gilles ${ }^{1}$
}

\footnotetext{
${ }^{1}$ Cognitive \& Affective Psychophysiology Laboratory, Department of Experimental Clinical and Health Psychology, Ghent University, Belgium

${ }^{2}$ Psychophysiology Laboratory, Institute of Psychology, Jagiellonian University in Krakow, Poland

${ }^{3}$ Research Group of Quantitative Psychology and Individual Differences, Center for Social and Cultural Psychology, KU Leuven, Belgium
}

Running head: Motivational significance of feedback

Corresponding address:

Mario Carlo Severo

Department of Experimental Clinical \& Health Psychology

Ghent University

Henri Dunantlaan 2

9000 Ghent

Belgium

email address: MarioCarlo.Severo@UGent.be

contact number: +3292649144 


\begin{abstract}
Performance monitoring (PM) entails the continuous evaluation of actions and their outcomes. At the electrophysiological level, PM has been consistently related to two event-related brain potentials (ERPs): the Feedback-Related Negativity (FRN) and the P3. In a previous withinsubject crossover design study, we showed that feedback's goal impact (i.e., its importance to one's goal) modulated these ERP components, yet in opposing directions. Although high goal impact was associated with a larger P3, the preceding FRN had a lower amplitude than in the low impact condition. We sought to extend these findings here by adopting a between-subjects design for a pure goal impact manipulation. Sixty-eight participants completed a Go/No Go Task while 64-channel electroencephalography was recorded concurrently. They were randomly assigned to either a high or low goal impact condition, manipulated through instructions on the supposed task's diagnosticity, while reward probability was kept similar between conditions. Replicating our previous results, we found that high goal impact yielded a marginally lower FRN, but substantially larger P3 during PM than low goal impact, without arousal or performance differences. Moreover, a principal component analysis confirmed these opposing directions of goal impact modulation. Overall, these results dovetail with the assumption that goal impact influences PM processes.
\end{abstract}

Keywords: ERP; FRN; P3; PCA; Performance monitoring; Goal impact 


\section{Introduction}

Performance monitoring (PM) is an utmost important cognitive process. Successful execution of goal-directed actions proves to be challenging in a continuously changing environment, especially because errors and conflicts are inevitable. Individuals must, therefore, rely on an adapted cognitive system that swiftly detects errors or conflicts and allows for implementation of corrective mechanisms to make sure goals are eventually achieved. It is for this reason that PM has been a ubiquitous subject of scientific inquiry for years (Koban \& Pourtois, 2014; Ullsperger, 2017; Ullsperger et al., 2014a, 2014b). Current models posit PM as a feedback loop in which discrepancies between the desired and actual action outcomes are evaluated to activate cascades of remedial processes and ensure optimal future outcome predictions (Ullsperger, 2017; Ullsperger et al., 2014b). This process is immensely dynamic and pliable as it exploits any information or cues relating to internal states (such as erroneous response) and external events or incentives (such as feedback indicating loss; Koban \& Pourtois, 2010; Ullsperger, 2017; Ullsperger et al., 2014a; 2014b).

An abundant body of event-related potential (ERP) research has implicated medial-frontal potentials that serve as electrophysiological signatures of the internal and external systems of PM. The internal or motor-based processing is best captured by two response-locked negativities: the Error-Related Negativity (ERN) and the Correct Related Negativity (CRN). The ERN is a phasic, negative deflection over the fronto-central electrodes along the midline elicited shortly after error commission (Falkenstein et al., 1990; Gehring et al., 1993). The CRN is a similar but smaller negative deflection usually observed after correct responses and elicited during a similar interval as the ERN (Allain et al., 2004; Vidal et al., 2000). In the case that internal evidence is lacking or has not properly accumulated, information from external feedback can also be exploited during PM (Ullsperger et al., 2014b; Walentowska et al., 2016). The external or feedback-based processing, which is the primary focus of this study, is 
manifested in the Feedback-Related Negativity (FRN). The FRN is a phasic, negative deflection over the fronto-central locations along the midline elicited by negative performance feedback at 250-300 ms after its onset, sharing many similarities with the ERN (Miltner et al., 1997). The amplitude of this component is suggested to be highly sensitive to the feedback valence, being larger for negative than positive feedback (Miltner et al., 1997; Nieuwenhuis et al., 2004), as well as for monetary losses than gains (Gehring \& Willoughby, 2002). Additionally, feedback expectedness seems to also modulate FRN amplitude, with unexpected feedback eliciting larger negativity than expected ones (Ferdinand et al., 2012; Hajcak et al., 2007; von Borries et al., 2013). Studies attempting to source-localize the FRN generator have usually pinpointed a dorsal region of the anterior cingulate cortex, which is also the main intracranial generator of the ERN (Gehring \& Willoughby, 2002; Gentsch et al., 2009; Cavanagh et al., 2010; Ullsperger, 2017).

The FRN is typically followed by a positive component referred to as P3 (Polich, 2007; Ullsperger, 2017; Ullsperger et al., 2014b). The P3 is a broad, positive deflection over a midline scalp distribution, peaking at 300-600 ms after stimulus onset (Desmedt et al., 1965; Polich, 2007; San Martin, 2012; Sutton et al., 1965). This component is observed to be highly sensitive to motivationally relevant events (Nieuwenhuis et al., 2005; San Martin, 2012). In PM studies, the increase in the P3 amplitude has been suggested to relate to greater processing of the motivational significance of the feedback or updating of the action value (Fischer \& Ullsperger, 2013; Ullsperger et al., 2014b; Ullsperger, 2017).

The functional significance of the FRN and P3 during PM remains to be a central question in the literature (Hajihosseini \& Holroyd, 2013; Proudfit, 2015; Ullsperger et al., 2014b; San Martin, 2012). With respect to the FRN, it is still debated whether amplitude variations of this early component of PM are associated with specific emotional features, specific cognitive features, or a blend of both. Some authors claim that FRN mainly codes for the feedback valence, independent of its expectedness (e.g., Hajcak et al., 2007; von Borries et al., 2013), 
whereas others posit that it codes for the feedback expectedness, irrespective of its valence (e.g., Donkers et al., 2005; Ferdinand et al., 2012; Oliveira et al., 2007). A recent, alternative proposal is that goal relevance is involved in the modulation of FRN amplitude, in addition to or instead of valence and expectedness alone (e.g., Gentsch et al., 2013; Osinsky et al., 2017; Bennett et al., 2016; Fischer \& Ullsperger, 2013; Severo et al., 2017; Walentowska et al., 2016). Goal relevance is a central construct in psychology and neuroscience that can account for a wide range of phenomena, including PM (Eitam \& Higgins, 2010; Frijda, 1986; Folk \& Remington, 2008; Moors, 2007; Mansouri et al., 2017). Under this framework, the evaluation of actions during PM can be viewed as not solely depending on their valence (whether they are congruent or incongruent with goals) or their expectedness (whether they are congruent or incongruent with expectations), but also on the degree to which they are relevant for our goals. In our previous work (Severo et al., 2017; Walentowska et al., 2016, 2018), we have scrutinized and dissected the concept of goal relevance into three partly dissociable factors: (a) task relevance, which is the degree to which the feedback stimulus allows for the implementation of a task goal, (b) goal impact, which is the degree of goal satisfaction (or dissatisfaction) signaled by the feedback stimulus and which likely depends on the value of the goal, and (c) goal informativeness or trustworthiness, which is the degree to which the feedback stimulus reliably informs about or signals goal satisfaction (or dissatisfaction).

In Severo et al. (2017), we capitalized on a within-subject crossover design experiment wherein the performance feedback for two tasks had either high or low impact on the goals of maintaining one's social status or self-esteem (i.e., the second meaning of goal relevance). Participants completed speeded versions of the Go/No Go Task (see Aarts \& Pourtois, 2012) and the Simon Task (Simon \& Rudell, 1967) that yielded similar reward probability (i.e., frequent negative feedback and infrequent positive feedback), but systematically differed in goal impact (by assigning high vs. low diagnosticity of the tasks for important life functioning 
and by the presence vs. absence of social comparison). The ERP results revealed amplitude modulation at the FRN and P3 levels in the absence of differences in arousal or task engagement of the participants (i.e., the behavioral indices) between the two goal impact conditions. When feedback had high impact (regardless of its valence), the FRN amplitude was generally decreased compared to the low impact condition. We tentatively interpreted this result as reflecting the activation of a self-protective strategy by the participants (Alicke \& Sedikides, 2011; Leary et al., 2009; Sedikides \& Green, 2009; Sherman \& Cohen, 2006). This selfprotection could have occurred because negative feedback prevailed throughout the session and could have threatened the participants' self-image or social status, especially in the high goal impact condition. Although speculative, this interpretation fits nicely with earlier studies showing that individuals use various defensive strategies to keep a positive view of themselves, especially when faced with threats and failures (Hoefler et al., 2015; Sedikides \& Green, 2004; Wentura \& Greve, 2004). An example of such recourse is deliberate ignorance (i.e., the intentional choice not to seek or use information), which has been suggested to have some benefits for learning and performance (Hertwig \& Engel, 2016; Huck et al., 2015; Shen et al., 2015).

Interestingly, this FRN effect was accompanied by an opposite P3 effect. Regardless of valence, a larger P3 amplitude was observed for the high than for the low impact condition, which possibly suggested the assignment of a higher motivational significance to the feedback in the former condition, despite the use of this self-protective strategy (Bellebaum et al., 2010; Gu et al., 2011; Nieuwenhuis et al., 2005). Taken together, the opposite ERP results suggest that the lower monitoring of feedback at the FRN level was however accompanied by a stronger processing of its motivational significance at the P3 level (Severo et al., 2017).

In the current study, we aimed to replicate and extend this pattern of ERP findings, using an improved methodology. One constraint of the previous design was that the goal impact 
manipulation (high vs. low) could not be fully orthogonalized with the type of experimental task (Go/No Go task vs. Simon task). As a result, it remained somewhat hard to disentangle the goal impact effect from task-specific effects. To overcome this potential problem, the current experiment adopted a between-subjects design experiment in which participants in both impact conditions carried out exactly the same task but only received different instructions regarding the task's diagnosticity for important life functioning. Moreover, we no longer presented comparative performance information in the current study. In this way, a pure goal impact effect was ensured and possible unwanted carry-over effects from one goal impact condition to another were avoided (although a control analysis including order as factor failed to confirm this interpretation in our previous study; see Severo et al., 2017).

We hypothesized that high compared to low impact would be associated with a lower FRN but larger P3 component (see Severo et al., 2017). Further, peripheral arousal and performance should be matched between the two groups, thereby ruling out the possibility that the observed effects at the ERP level during PM could simply be explained by these factors. To assess whether our goal impact manipulation produced measurable changes at the conscious level, we also used a short version of the Intrinsic Motivation Inventory (IMI; Ryan, 1982), where we contrasted ratings prior to and after task execution for the two groups separately. For completeness, we also analyzed and reported the results for the response-locked ERP component data (i.e., ERN and CRN).

\section{Materials and Methods}

\subsection{Participants}

Seventy-eight healthy, right-handed, university students with normal or corrected-tonormal vision, who did not report neurological or psychiatric diseases or treatment, were recruited in the current study. They were randomly assigned to one out of two goal impact 
conditions (i.e., high vs. low impact). Ten participants had to be removed from the analysis due to the following reasons: One had been exposed to the same task in another experiment prior to the current testing, four had excessive noise and artifacts during the electrophysiological recording, and five had poor task performance ${ }^{1}$. This resulted in a total sample of 68 participants $^{2}$. Table 1 summarizes the main characteristics of the participants for the two impact conditions. All participants received a fixed $€ 20$ compensation and gave written informed consent. The study was approved by the local ethics committee of Ghent University.

\begin{tabular}{l|ccccc}
\hline & HIGH IMPACT & LOW IMPACT & $t$-test & $p$ & $d$ \\
\hline$N$ & 34 & 34 & & \\
\hline Age & $22.76( \pm 2.87)$ & $22.65( \pm 2.95)$ & 0.16 & 0.868 \\
\hline Gender ratio & $23 \mathrm{~F} / 11 \mathrm{M}$ & $22 \mathrm{~F} / 12 \mathrm{M}$ & & & \\
\hline BIS/BAS scales & & & & & \\
\hline BAS - Drive & $11.03( \pm 2.73)$ & $12.29( \pm 2.30)$ & -2.07 & $0.042^{\mathrm{a}}$ & -0.503 \\
\hline BAS - Fun-Seeking & $11.97( \pm 2.14)$ & $12.47( \pm 2.00)$ & -0.99 & -0.241 \\
\hline BAS - Reward Responsiveness & $17.53( \pm 2.05)$ & $17.35( \pm 2.53)$ & 0.32 & 0.753 & 0.077 \\
\hline BIS & $23.29( \pm 3.10)$ & $21.97( \pm 4.92)$ & 1.33 & 0.189 & 0.322 \\
\hline LSAS & $48.8( \pm 16.49)$ & $39.9( \pm 19.53)$ & 2.05 & $0.045^{\mathrm{b}}$ & 0.496 \\
\hline RSES & $19.68( \pm 4.99)$ & $19.59( \pm 5.60)$ & 0.07 & 0.946 & 0.017 \\
\hline
\end{tabular}

Table 1. Participant sample and characteristics. The table summarizes the sample size, the age, the gender ratio, and the dispositional measure scores of participants in each of the two impact groups. The means (standard deviations) are provided. Independent samples $t$-test differences are reported for the BIS/BAS scales, with the corresponding subscales $(\mathrm{df}=66)$, LSAS $(\mathrm{df}=66)$, and RSES $(\mathrm{df}=66)$. ${ }^{\text {a }}$ Note that a Bonferroni correction was applied to control for the familywise error rate of the BIS/BAS scales (from the 4 subscales compared). ${ }^{\mathrm{b}}$ An additional control analysis was performed to confirm that the group difference found at the P3 level was mostly explained by the goal impact manipulation, but not by this unexpected group difference along the LSAS (see footnote pp. 22-23).

\footnotetext{
${ }^{1}$ Hit rate accuracy of these participants was 3 S.D. below the mean of the group; hence, they were considered outliers.

${ }^{2}$ The final sample size $(N=68)$ was determined via a power analysis performed in MorePower v. 6.0 (Campbell \& Thompson, 2012). The calculation was based on the effect size of our previous study (Severo et al., 2017) used as prior and a power of $80 \%$.
} 


\subsection{Experimental design}

We devised a between-subjects design experiment in which two groups performed a speeded version of an extensively validated Go/No Go Task (see Aarts \& Pourtois, 2010, 2012; Koban et al., 2012; Pourtois, 2011; Severo et al., 2017; Vocat et al., 2008; Walentowska et al., 2016, 2018). Like in our previous study (Severo et al., 2017), this task was presented as a selfregulation measure. We assumed that feedback of performance on this task would impact on participant's goal for self-esteem, a goal that is valued by most people (see Baumeister et al., 2003; Rosenberg et al., 1995). Importantly, the two groups were relayed different instructions on the diagnosticity of the task for successful life functioning. Participants in the high impact group were informed that current scientific research shows a positive link between selfregulation ability and academic grades amongst students. Moreover, an autobiographical recall technique (Selimbegovic et al., 2011) was employed to further prime the goal of maintaining good self-regulation ability: They were asked to recall a specific real-life experience in which they successfully exerted self-regulation. Participants in the low impact group were neither provided with information about the relationship of the task to academic success nor were they submitted to the autobiographical recall technique. We assumed that the different treatments in both conditions would induce different degrees of impact of the performance feedback on the goal for self-esteem. Although both groups had the impression of doing a task that is relevant for their self-esteem (diagnostic of self-regulation), only participants in the high impact condition took it as an indicator of an important life function (academic success). This should make performance monitoring more compelling for participants in this condition.

\subsection{Stimuli and task}

The Go/No Go task was programmed in E-prime V2.0 (Psychology Software Tools Inc., Sharpsburg, PA), and was presented on a 21-inch CRT screen. This task entailed participants to respond as fast and as accurately as possible before an arbitrary deadline so as to receive 
positive feedback. An online adaptive algorithm was used to systematically vary the response deadline trial by trial, creating high uncertainty in deciphering one's reaction times (RTs). The ambiguity of the RTs enforced participants to rely on the external feedback stimulus to infer whether the outcome of their actions was positive or goal congruent (i.e., the response was correct and fast), or not (i.e., the response was correct but too slow or it was incorrect).

Fig. 1A depicts a sample trial sequence of the task. A fixation cross on a white background appeared on the screen for $500 \mathrm{~ms}$ to indicate the beginning of a trial. This was followed by an upward- or downward-orienting black arrow that served as a 'cue', jittered at a duration between 1000 to $2000 \mathrm{~ms}$. The change in the color and orientation of this cue afterwards critically defined the trial type: On Go trials, a green arrow with an unchanged orientation served as a 'target' that required a quick press of a predefined key on the response box with the index finger of the right hand. On No Go trials, a green arrow with a flipped orientation or a turquoise arrow with an unchanged orientation served as 'non-targets' that required suppression of a key press. Both the target and non-targets were displayed on a white background at a maximum duration of $1000 \mathrm{~ms}$. A black frame appeared around the target (or the non-target) for $1000 \mathrm{~ms}$ to signify that a response/press was made, regardless of accuracy. This event served as a response-feedback interval. In the absence of a key press, the target (or the non-target) was shown without a black frame at its maximum duration. The trial concluded with the presentation of a symbolic feedback stimulus for $1000 \mathrm{~ms}$. On each and every trial, participants received one out of three possible color-coded dots on a white background centered on the screen as feedback stimulus (see Fig. 1B) subsequent to the given response or withdrawal from response. A green dot, signifying positive feedback, was presented for correct and fast responses to Go trials ('fast hit') and successful withholding of responses to No Go trials ('correct inhibition'). A red dot, indicating negative feedback, was provided for correct but slow responses ('slow hit') or a lack of responses ('omission') to Go trials and non-inhibition of responses ('false alarm') to No Go 
trials. Finally, a colorless dot was given for a small portion of fast and slow hits to Go trials. Participants were informed beforehand that they would see this feedback because at times the program could not quickly delineate fast and slow responses given the speeded nature of the task. Hence, this rare feedback was not informative about the speed of their response (i.e., they were either fast or slow). This feedback type was added to provide an indirect check that the high impact goal would not simply be associated with a reduced processing of feedback in general. However, we reckoned that because of the low probability of this feedback type, the corresponding ERP components would be qualitatively different compared to the ones recorded for the more regular informative (negative or positive) feedback. The task consisted of 4 blocks, each having 62 trials. The trial types were in the following proportions: 46 Go trials and 16 No Go trials. The Go trials were further subdivided into 40 typical trials in which participants received either a positive or a negative feedback contingent to their actual response, while the remaining 6 were trials on which they received uninformative feedback.

We implemented an online adaptive algorithm previously developed by Vocat et al. (2008). Participants were not informed about the algorithm that determined the response deadline procedure in the Go trials. The RT limit was set to $300 \mathrm{~ms}$ at the start of each block. Thereafter, this limit was calibrated trial by trial based on the average of the current and previous RT. The calibration ensured stringent delineation of fast and slow hits, leading to a smaller percentage of the former (1/3) than the latter (approximately 2/3). Accordingly, positive feedback was less frequent compared to negative feedback. The implementation of this algorithm proved to be advantageous in motivating participants to rely on the feedback stimulus provided to them on every trial. Additionally, it encouraged high involvement in the task as reward probability was low, and self-efficacy was therefore challenged (Aarts \& Pourtois, 2010, 2012; Atkinson \& Feather, 1966; Dhar \& Pourtois, 2011; Dhar et al., 2011; Koban et al., 2010; 2012; Vocat et al., 2008; Walentowska et al., 2016, 2018). 


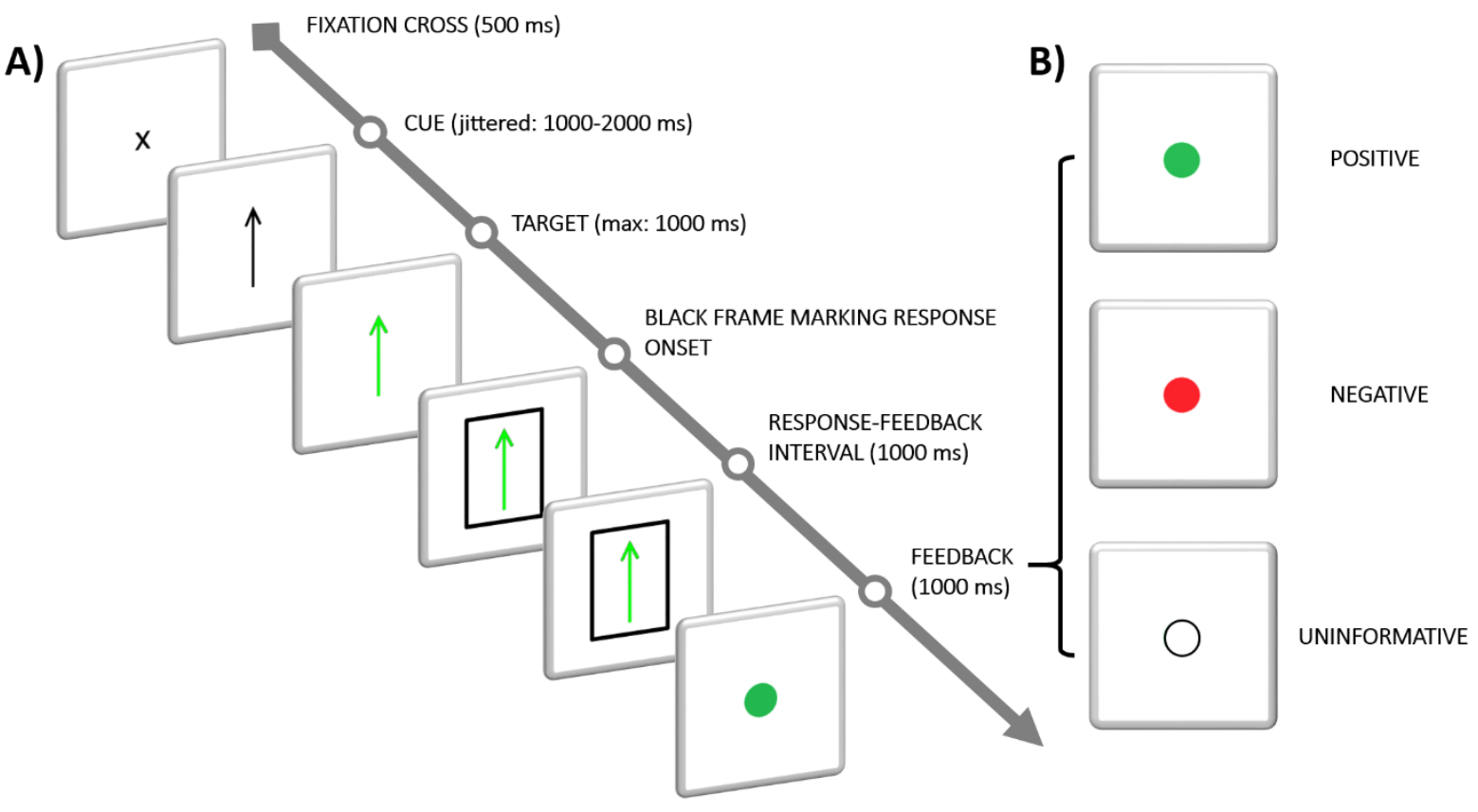

Figure 1. Speeded Go/No Go Task trial sequence. (A) An illustration of a sample trial sequence of the task for a Go trial followed by a hit (see Methods): Every trial started with a fixation cross displayed for $500 \mathrm{~ms}$, followed by a black arrow that served as a cue in a jittered duration of 1000 to $2000 \mathrm{~ms}$. The target ensued for a maximum duration of $1000 \mathrm{~ms}$. Participants were instructed to press a predefined key of the response box as quick as possible. A black frame around the target marked the key press and remained on the screen for $1000 \mathrm{~ms}$ as a responsefeedback interval. Lastly, a color-coded dot that served as a feedback stimulus was provided to the participants consequent to their motor response. (B) Three types of feedback stimuli were used: a green dot signifying positive feedback for fast hits and correct inhibitions, a red dot indicating negative feedback for slow hits, false alarms, and omissions, and a colorless dot denoting uninformative feedback for a small portion of Go trials (i.e., 6 out of the 46 trials in a block). Participants were informed beforehand that they would see this rare feedback because the program at times cannot swiftly delineate fast from slow responses given the speeded nature of the task.

\subsection{Subjective ratings}

We used two sets of questions. A first set of questions were taken from the Intrinsic Motivation Inventory (IMI; Ryan, 1982) and probed for differences in the groups' overall experience of the task. We presented questions asking about the amount of effort participants put in the task to be able to examine the self-protection account. This account was inspired by earlier studies demonstrating the tendency of individuals to discount performance against selfthreatening information to protect a generally held positive self-view (e.g., Frankel \& Snyder, 1978; Miller, 1976; Pyszczynski \& Greenberg, 1983). A second set of questions probed for 
differences in the groups' experiences of the performance feedback. Specifically, we asked our participants to evaluate their actions and how much they liked each of the feedback types.

\subsubsection{IMI}

The IMI is a multidimensional measure for self-reported experience to a target activity in experiments (Ryan, 1982). It taps into motivational constructs central to the Self-Determination Theory (see Ryan \& Deci, 2000) and has been employed in various self-regulation and intrinsic motivation studies (e.g., Deci et al., 1994; Plant \& Ryan, 1985; Ryan, 1982; Ryan et al., 1990, 1991, 1983). It consists of seven subscales (which are each comprised of a varied number of items): interest/enjoyment, perceived competence, effort, value/usefulness, felt tension, perceived choice, and relatedness to others. Individuals rate these dimensions concerning an experimental task or activity (McAuley et al., 1989; Ryan, 1982).

We selected seven items of this questionnaire and asked participants of both impact groups to rate them both prior to the Go/No Go Task (pre-IMI; once some practice trials were completed) and after its completion (post-IMI). The items were: (1) 'I put a lot of effort into this task', (2) 'I am satisfied with my performance at this task', (3) 'I believe this activity could be of some value to me', (4) 'I thought this activity was quite enjoyable', (5) 'I did this activity because I wanted to', (6) 'It was important to me to do well at this task', and (7) 'I felt very tense while doing this activity.' Note, however, that the items were formulated in the future tense for the pre-IMI (except item 7) in anticipation of the task (e.g., 'I want to put a lot of effort into this task'). Each item was rated on a 7-point Likert scale, ranging from 1 (not at all true) over 4 (somewhat true) to 7 (very true). Items 1 and 6 played a crucial role in this study. These were the items subsumed by the effort/importance subscale of the IMI.

\subsubsection{Feedback evaluation}

Similar to our previous study (Severo et al., 2017), we probed for possible differences between the two impact groups with regard to their evaluation of their actions and liking of the 
feedback types. Participants rated the following questions relating to: (1) disliking committing errors ('How much did you dislike making errors in this task?'), (2) liking making correct responses ('How much did you like making correct responses in this task?'), (3) disliking receipt of negative feedback ('How much did you dislike receiving negative feedback in this task?'), (4) liking receipt of positive feedback ('How much did you like receiving positive feedback in this task?'), (5) informativeness of the feedback ('In general, how important was the feedback to inform your behavior, i.e., accuracy and speed?'), and (6) (dis)liking of the uninformative feedback ('How much did you dislike/like the neutral feedback?'). Ratings were obtained using visual analog scales (VAS), which ranged from 0 (not at all) to 100 (a lot) for items 1 to 5, and from 0 (dislike) to 100 (like) for item 6 .

\subsection{Procedure}

Participants attended the session individually. They signed an informed consent and were prepared for the recording. The experimenter attached the electroencephalography (EEG) and electrocardiography (ECG) sensors to the participants and guided them to a dimly lit, soundattenuated, and electrically-shielded cabin for the testing. The entire experimental procedure was computerized and was administered to them while seated at a viewing distance of $\sim 80 \mathrm{~cm}$ from the monitor. The session proceeded with the 5-min resting-state ECG recording to determine the baseline arousal level of the participants. Afterwards, they were informed that the study was about self-regulation. The manipulation of goal impact was carried out at this point, with the two impact groups receiving different information about the importance of selfregulation and the task (see here above). Next, both impact groups were exposed to a procedure aimed at fostering autonomous motivation (see Legault \& Inzlicht, 2013). This was inspired by numerous studies that suggested the role of autonomy in enhancing goal-related performance and self-regulatory pursuits in several domains (e.g., Guay et al., 2008; Legault \& Inzlicht, 2013; Moller et al., 2006; Vansteenskiste et al., 2004). In line with the study of Legault and 
Inzlicht (2013), participants in both impact groups were introduced to three tasks presented as measuring their self-regulation ability and were asked to select one of them that they wanted to complete for the session. Unbeknownst to them, each of the options eventually led to the same task (i.e., Go/No Go Task). Participants received instructions about the chosen task, which included information on the diagnosticity of the performance score for future outcomes. Participants were informed that they would receive a score, which was a combination of their speed and accuracy. The score was delivered cumulatively and was averaged across the blocks. The average score was communicated to the participants as their overall performance score. They were told that an overall performance score above $40 \%$ would mean excellent selfregulation ability (while a score below this benchmark would mean poor ability). Participants conducted a practice run of 34 trials to familiarize them with the task, followed by the pre-IMI questions. Participants subsequently completed four blocks of the task and were presented with their overall performance scores. This was followed by the administration of the post-IMI questions and the questions probing for feedback evaluation. The session concluded with another 5-min resting-state ECG recording to determine the post-task arousal level of the participants. Once all the electrophysiological sensors had been removed, participants filled out Dutch versions the Behavioral Approach System/Behavioral Inhibition System Scales (BIS/BAS; Carver \& White, 1994; Franken, 2002), the Liebowitz Social Anxiety Scale (LSAS; Liebowitz, 1987; van Vliet, 1999), and the Rosenberg Self-Esteem Scale (RSES; Rosenberg, 1965; Franck et al., 2008). A debriefing email was sent to them after all participants had been tested.

\subsection{Data acquisition}

The EEG and ECG were recorded continuously throughout the experiment at a sampling rate of 512-Hz using a BIOSEMI Active-Two system (BioSemi B. V., Amsterdam, the Netherlands) with $64 \mathrm{Ag}-\mathrm{AgCl}$ (silver-silver chloride) electrodes. The CMS (Common Mode 
Sense) and DRL (Driven Right Leg) electrodes were used online as reference and ground electrodes. The 64 EEG electrodes were mounted in an elastic cap in accordance with the extended International 10-20 EEG system. The 2 ECG electrodes were attached on the left side of the chest cavity, one just below the right clavicle and the other on the lower torso. The vertical and horizontal electrooculogram (EOG) signals were monitored from 4 auxiliary electrodes placed above and below the left eye and on the outer canthi of both eyes, respectively. Another 2 auxiliary electrodes were placed on the left and right mastoids.

\subsection{Data reduction and analysis}

\subsubsection{ECG}

The raw ECG signal was processed offline using Brain Vision Analyzer 2.0 (Brain Products, GmbH, Munich, Germany), following a standard data transformation sequence (Laborde et al., 2017; Task Force of the European Society of Cardiology and the North American Society of Pacing and Electrophysiology, 1996). First, a standard subtraction procedure was applied to the signal to determine the difference between the two ECG electrodes. Next, the data were segmented to the following epochs of interest: (a) baseline recording, (b) task blocks recording, and (c) post-task recording. Then, the segments were subjected to a heart rate variability (HRV) analysis using ARTiiFACT software (Kaufmann et al., 2011). HRV serves as a marker for small beat-to-beat changes in the heart rate due to the interplay of the sympathetic and parasympathetic branches of the autonomic nervous system (Appelhans \& Luecken, 2006; Lane et al., 2009; Task Force of the European Society of Cardiology and the North American Society of Pacing and Electrophysiology, 1996; Thayer et al., 2009). The analysis began with an automated R-peak detection and IBI extraction. Afterwards, the extracted IBIs underwent artifact detection and correction via cubic spline interpolation of neighboring IBIs. Then, from the corrected IBIs, the root mean square of 
successive difference (RMSSD) values were determined. The RMSSD is the most frequently employed HRV parameter in the time domain (Task Force of the European Society of Cardiology and the North American Society of Pacing and Electrophysiology, 1996). This parameter was further submitted to a $\log$ transformation $(\log 10)$ to adjust for the unequal variance prior to statistical analysis (Laborde et al., 2017). A lower RMSSD during the experimental task relative to the baseline recording suggests an increased arousal level. Conversely, a higher RMSSD during the experimental task relative to the baseline recording indicates a decreased arousal level.

\subsubsection{EEG}

\subsubsection{Preprocessing}

The raw EEG signal was processed offline using Brain Vision Analyzer 2.0, following a standard data transformation sequence (Keil et al., 2014). First, the signal was notch-filtered at 50-Hz whenever deemed necessary and was re-referenced via linked-mastoids. Bad channels were interpolated using a spherical spline interpolation technique (order of splines $=4$, max. degree of Legendre polynomials $=10$, lambda $=1 \mathrm{e}-5$ ). The interpolation was limited to 6 electrodes (which constitutes $9.3 \%$ of the total channels). Then, a high-pass filter of $.1 \mathrm{~Hz}$ with a roll-off slope of $24 \mathrm{~dB} /$ octave (i.e., fourth-order filter) was applied. Next, the data were segmented to the following epochs of interest: (a) -500/+1000 ms segmentation around the stimulus onset for feedback-locked ERPs and (b) -500/+500 ms segmentation around the response onset for response-locked ERPs. The segmented data were then subjected to an eyeblink artifact correction (Gratton et al., 1983) and to a baseline correction comprised of (a) a pre-stimulus baseline correction (from $-500 \mathrm{~ms}$ to feedback onset) and (b) a pre-response baseline correction (from -500 to $-300 \mathrm{~ms}$ prior to the response onset). Then, a semi-automatic artifact rejection was implemented by applying a criterion of $\pm 100 \mu \mathrm{V}$. Averaging of ERPs 
ensued, with the feedback-locked ERPs averaged per each feedback type and impact condition and the response-locked ERPs averaged per each response type and impact condition. Table 2 summarizes the number of trials retained for ERP averaging per condition, along with the standard deviation and minimum number used. Finally, a 30-Hz low-pass digital filter with a roll-off slope of $24 \mathrm{~dB} /$ octave was applied to the averaged ERPs.

\begin{tabular}{|c|c|c|c|c|}
\hline \multicolumn{5}{|c|}{ IMPACT } \\
\hline ERPs & $\mathrm{HIGH}$ & LOW & $t$-test & $p$ \\
\hline \multicolumn{5}{|l|}{ 1. Feedback-locked ERP } \\
\hline - $\quad$ Negative feedback & $77( \pm 18.8 ; 41)$ & $84( \pm 23.2 ; 36)$ & -1.496 & 0.139 \\
\hline - $\quad$ Positive feedback & $47( \pm 15.8 ; 16)$ & $44( \pm 15.6 ; 15)$ & 0.735 & 0.465 \\
\hline - Uninformative feedback & $20( \pm 2.9 ; 12)$ & $21( \pm 3.4 ; 11)$ & -0.382 & 0.703 \\
\hline \multicolumn{5}{|l|}{ 2. Response-locked ERP } \\
\hline - $\quad$ Errors & $19( \pm 9.7 ; 8)^{*}$ & $18( \pm 7.7 ; 7)$ & 0.761 & 0.449 \\
\hline - Hits (collapsed Fast \& Slow Hits) & $131( \pm 23.8 ; 47)$ & $136( \pm 19.4 ; 96)$ & 1.997 & 0.349 \\
\hline
\end{tabular}

Table 2. Mean number of trials retained per ERP and condition. The table summarizes the number of trials used for ERP averaging (i.e., either feedback-locked or response-locked) per condition, with the means $( \pm 1$ SD and minimum) reported separately for the two impact groups. Statistical analyses confirmed that both groups had similar numbers of trials/segments included in the ERP averages per condition, as indicated by the corresponding t-test and p value. *One subject did not have enough error trials for averaging. This missing data was replaced by the condition-specific average of the group.

\subsubsection{ERPS}

The quantification of the ERP components was primarily based on our prior work (Severo et al., 2017; Walentowska et al., 2016), particularly for the a priori selection of the time windows and electrode positions. For both impact groups, the feedback-locked ERPs included the positive feedback following fast hits, the negative feedback following slow hits, and the uninformative feedback. Feedback following correct inhibitions and false alarms were excluded from the analysis because (a) they lacked systematic post-feedback onset ERP effects, (b) they 
were rare events, and (c) they were deemed uninformative because participants could easily assess accuracy of their actions by relying mainly on internal monitoring (see Koban et al., 2012 for a clear demonstration). We extracted the FRN and P3 components from the feedback-locked ERPs. Previous ERP studies have reported maximum FRN amplitude at fronto-central electrode locations (Ullsperger et al., 2014a). Therefore, we measured the mean voltage of the amplitude of FRN at channel FCz between $250-300 \mathrm{~ms}$ after feedback onset for all the feedback types ${ }^{3}$. We determined the mean voltage of the amplitude of the P3 component at channel Pz between 300-400 ms after feedback onset for the positive and negative feedback. A similar quantification of component was performed for the uninformative feedback, but at a later time window. A visual inspection revealed a delayed P3 peak for this feedback type. Therefore we extracted the component instead between 440-540 ms after feedback onset. The values for the positive and negative feedback were tested separately from the values for the uninformative feedback type. The FRN and P3 amplitude values exceeding 2.5 standard deviations from the mean of valencespecific conditions of each impact group were treated as outliers. These outlier data points corresponded to $2.45 \%$ of the entire data set for the FRN (i.e., $\mathrm{n}=5$ across three feedback-type conditions for the two impact groups) and to $0.49 \%$ for the P3 (i.e., $n=1$ across three feedbacktype conditions for the two impact groups). The data were then interpolated using the mean of valence-specific conditions of each impact group prior to statistical testing.

For the response-locked ERP data, we extracted the ERN from response errors corresponding to false alarms on the no-go trials, and the CRN from combined fast and slow hits corresponding to correct key presses on the go trials. Earlier ERP studies have reliably demonstrated maximum ERN (and CRN) amplitude at fronto-central electrode sites (Falkenstein et al., 2000; Holroyd \& Coles, 2002; Koban et al., 2010, 2012; Nieuwenhuis et al., 2001). Hence, we quantified the mean voltage of the amplitude of ERN (and CRN) at channel

\footnotetext{
${ }^{3}$ We also performed an alternative scoring method for the FRN (i.e., peak-to-peak) for direct comparison to our previous work (Severo et al., 2017; see Supplementary Materials for details).
} 
FCz between $10 \mathrm{~ms}$ prior to and $50 \mathrm{~ms}$ after response onset. The ERN/CRN amplitude values exceeding 2.5 standard deviations from the mean of response-specific conditions of each impact group were treated as outliers. These outlier data points corresponded to $2.21 \%$ of the entire data set (i.e., $n=3$ across the two response-type conditions for the two impact groups. The data were also interpolated using the mean of response-specific conditions of each impact group prior to statistical testing.

\subsubsection{Principal Component Analysis (PCA)}

To disentangle the FRN from the P3 component, a principal component analysis (PCA) was carried out using the ERP PCA Toolkit (EP Toolkit, version 2.68; Dien, 2010a) in Matlab R2013b (MathWorks Inc., Natick, MA, USA). We used this PCA to confirm that the FRN and P3, although following each other rapidly after feedback onset, had dissociable electrophysiological properties (i.e., each of them could be best captured by a specific temporospatial factor), and eventually showed opposing effects of goal impact (i.e., lower FRN but larger P3 when goal impact was high compared to low). The EP Toolkit is an open source MATLAB-based toolbox intended for multivariate decomposition and analysis of ERP data (Dien, 2010a). A recommended two-step sequential PCA (Spencer, Dien, \& Donchin, 1999, 2001) was performed on each subject's feedback-locked ERPs. First, a temporal Promax rotation was implemented to capture the variance across the time points from the average ERP data, followed by a spatial Infomax (ICA) rotation to obtain the variance of the spatial distribution of the data across the 64 recording sites (Dien, 2010b).

Eight temporal factors $\mathrm{x}$ four spatial factors were extracted from the ERP data based on the Scree plot, yielding 32 temporospatial factor combinations. After this, an automated windowing step was implemented to further reduce the factors by screening out those factors whose variance accounted for did not meet the minimum threshold of $0.5 \%$. The PCA factors that survived this step were chosen for robust statistical testing. Importantly, we only considered for 
testing those factors that corresponded to the FRN and P3 components in terms of their time course and scalp distribution. This was performed by reconstructing the PCA factors back in voltage space in order for them to be transparently evaluated as ERP waveforms (Dien, 2010b). To better characterize them as corresponding to these ERP components, the voltage accounted for at the peak time point and channel of the factors was examined. One factor was recognized to closely correspond to the FRN component because its amplitude peaked within the time window of this component (i.e., 250-300 ms), and was most prominent at the fronto-central area. Three other factors were identified to closely correspond to the P3 component because their amplitudes peaked within the time window typical for this broad component (i.e., 300-600 $\mathrm{ms}$ ), and were most prominent from the fronto-central to the parietal area.

\subsection{Statistical analyses}

All statistical analyses were performed in JASP 0.7.0.5.6 (Love et al., 2015). To analyze the behavioral and electrophysiological data, we carried out mixed model ANOVAs that included between-subjects and within-subject factors. For the subjective ratings, we ran ANOVAs for the IMI ratings and an independent samples $t$-test for the VAS ratings. The ANOVAs for the former were ran independently for each of the questionnaire items and included the within-subject factor PHASE (pre-IMI vs. post-IMI) and the between-subjects factor IMPACT (high vs. low impact groups). For the behavioral data, the ANOVA included the within-subject factor RESPONSE (fast hit vs. slow hit; post-correct vs. post-error) and between-subjects factor IMPACT. For the HRV, the ANOVA included the within-subject factor PHASE (baseline recording vs. task blocks recording vs. post-task recording) and the between-subjects factor IMPACT. For the feedback-locked ERPs, we performed an ANOVA for the components quantified from the positive and negative feedback and an independent samples $t$-test for those quantified from the uninformative feedback. The ANOVA for the former included the between-subjects factor of IMPACT and the within-subject factor of 
VALENCE (positive vs. negative). Finally, for the response-locked ERP components, the ANOVA included the between-subjects factor of IMPACT and the within-subject factor of RESPONSE (errors/ERN vs. hits/CRN). Significant main or interaction effects were reported first, followed by post-hoc $t$-tests when applicable.

The statistical analysis of the PCA factors was performed using the robust statistics function of the EP toolkit. This function yields a statistical test comparable to ANOVAs that are robust against violations of statistical assumptions (Dien, 2010a), avoiding problems of conventional ANOVAs on ERP data (Dien \& Santuzzi, 2005). As outlined by Dien (2010a), the function contains as features: (a) trimmed means and winsorized covariances that protect against outliers; (b) a bootstrapping routine that estimates the population distribution instead of making assumption of the normality of this distribution; (c) a Welch-James approximate degrees-offreedom statistic that does not assume the homogeneity of error variance (this statistic sometimes leads to decimal degrees of freedom). The robust statistics function that we carried out included the within-subject factor of VALENCE and the between-subjects factor of IMPACT. The $p$-value was adjusted with the Bonferroni correction for multiple comparisons.

\section{Results}

\subsection{Subjective ratings}

\subsubsection{IMI}

The pre- and post-IMI ratings for Item 1 (i.e., putting effort into the task; see Fig. 2) revealed a significant main effect of IMPACT, $F_{(1,66)}=4.025, p=0.049, \eta_{\mathrm{p}}{ }^{2}=0.057$, but not of PHASE, $\mathrm{F}_{(1,66)}=0.024, \mathrm{p}=0.878, \eta_{\mathrm{p}}^{2}=0$. The low impact group reported greater effort to complete the task than the high impact group. Both impact groups did not demonstrate a considerable difference between their ratings prior to $\left(\mathrm{M}_{\text {highimpact }}=5.71, \mathrm{SEM}=0.17 ; \mathrm{M}_{\text {lowimpact }}\right.$ $=6.12, \mathrm{SEM}=0.15)$ and after task performance $\left(\mathrm{M}_{\text {highimpact }}=5.71, \mathrm{SEM}=0.15 ; \mathrm{Ml}_{\text {owimpact }}=\right.$ 
6.09, SEM = 0.15). No significant PHASE $x$ IMPACT interaction was found, $F_{(1,66)}=0.024, p$ $=0.878, \eta_{\mathrm{p}}^{2}=0$.

The ratings for Item 2 (i.e., satisfaction on the task performance; see Fig. 2) showed a significant main effect of PHASE, $\mathrm{F}_{(1,66)}=442.21, \mathrm{p}<0.001, \eta_{\mathrm{p}}^{2}=0.870$, but not of IMPACT, $\mathrm{F}_{(1,66)}=0.841, \mathrm{p}=0.362, \eta_{\mathrm{p}}^{2}=0.013$. Both impact groups reported a drop in satisfaction ratings from the moment of anticipation of the task $\left(\mathrm{M}_{\text {highimpact }}=6.15, \mathrm{SEM}=0.16 ; \mathrm{M}_{\text {lowimpact }}=6.47\right.$, $\mathrm{SEM}=0.12)$ until after its execution $\left(\mathrm{M}_{\text {highimpact }}=2.38, \mathrm{SEM}=0.17 ; \mathrm{M}_{\text {lowimpact }}=2.35, \mathrm{SEM}\right.$ $=0.23$ ), suggesting that both impact groups experienced the task as fairly demanding. No significant PHASE x IMPACT interaction was evident, $F_{(1,66)}=0.887, p=0.350, \eta_{p}^{2}=0.013$.

Similarly, the ratings for Item 3 (i.e., perceived value of the task; see Fig. 2) indicated a significant main effect of PHASE, $\mathrm{F}_{(1,66)}=28.07, \mathrm{p}<0.001, \eta_{\mathrm{p}}^{2}=0.298$, but not of IMPACT, $\mathrm{F}_{(1,66)}=1.842, \mathrm{p}=0.179, \eta_{\mathrm{p}}^{2}=0.027$. Both impact groups rated the value of the task higher before its implementation $\left(\mathrm{M}_{\text {highimpact }}=4.50, \mathrm{SEM}=0.22 ; \mathrm{M}_{\text {lowimpact }}=4.94, \mathrm{SEM}=0.23\right)$ in contrast to its completion $\left(\mathrm{M}_{\text {highimpact }}=3.85, \mathrm{SEM}=0.24 ; \mathrm{M}_{\text {lowimpact }}=4.21, \mathrm{SEM}=0.22\right)$. The PHASE x IMPACT interaction did not show a significant effect, $F_{(1,66)}=0.114, p=0.736, \eta_{p}^{2}$ $=0.002$.

The ratings for Item 4 (i.e., enjoyableness of the task; see Fig. 2) also exhibited a significant main effect of PHASE, $\mathrm{F}_{(1,66)}=36.20, \mathrm{p}<0.001, \eta_{\mathrm{p}}^{2}=0.354$, but not of IMPACT, $\mathrm{F}_{(1,66)}=$ $0.002, \mathrm{p}=0.964, \eta_{\mathrm{p}}{ }^{2}=0$. The two impact groups similarly experienced the task as more enjoyable prior to $\left(\mathrm{M}_{\text {highimpact }}=4.59, \mathrm{SEM}=0.26 ; \mathrm{M}_{\text {lowimpact }}=4.68, \mathrm{SEM}=0.25\right)$ compared to after having been exposed to it $\left(\mathrm{M}_{\text {highimpact }}=3.88, \mathrm{SEM}=0.25 ; \mathrm{M}_{\text {lowimpact }}=3.82, \mathrm{SEM}=0.24\right)$. Furthermore, no significant PHASE x IMPACT interaction was noted, $\mathrm{F}_{(1,66)}=0.322, \mathrm{p}=$ $0.572, \eta_{\mathrm{p}}^{2}=0.005$ 
The ratings for Item 5 (i.e., autonomy in task selection; see Fig. 2) did not indicate a significant main effect of PHASE, $F_{(1,66)}=0.240, p=0.626, \eta_{p}^{2}=0.004$, nor of IMPACT, $F_{(1,66)}$ $=1.136, \mathrm{p}=0.290, \eta_{\mathrm{p}}{ }^{2}=0.017$. A significant PHASE $\mathrm{x}$ IMPACT interaction was found, $\mathrm{F}_{(1,66)}$ $=4.508, \mathrm{p}=0.037, \eta_{\mathrm{p}}^{2}=0.064$. However, the post-hoc $t$ test revealed only a trend significant difference in the ratings between the two groups at baseline, $\mathrm{t}_{(66)}=-1.727, \mathrm{p}=0.089, \mathrm{~d}=-0.419$, $\left(\mathrm{M}_{\text {highimpact }}=5.35, \mathrm{SEM}=0.21 ; \mathrm{M}_{\text {lowimpact }}=5.85, \mathrm{SEM}=0.19\right)$ and no significant difference after completing the task, $\mathrm{t}_{(66)}=-0.371, \mathrm{p}=0.711, \mathrm{~d}=-0.090,\left(\mathrm{M}_{\text {highimpact }}=5.50, \mathrm{SEM}=0.22\right.$; $\left.\mathrm{M}_{\text {lowimpact }}=5.61, \mathrm{SEM}=0.23\right)$. It is worth noting, however, that the large mean values for this item in both groups suggest that participants consistently perceived the task as a self-determined one.

The ratings for Item 6 (i.e., importance of performing well on the task; see Fig. 2) produced a significant main effect of PHASE, $\mathrm{F}_{(1,66)}=4.274, \mathrm{p}=0.043 \eta_{\mathrm{p}}{ }^{2}=0.061$, but not of IMPACT, $\mathrm{F}_{(1,66)}=1.828, \mathrm{p}=0.181, \eta_{\mathrm{p}}^{2}=0.027$. In comparison to the baseline $\left(\mathrm{M}_{\text {highimpact }}=5.41, \mathrm{SEM}=\right.$ $\left.0.25 ; \mathrm{M}_{\text {lowimpact }}=5.76, \mathrm{SEM}=0.19\right)$, both impact groups showed a slight increase in their ratings after having been exposed to the task $\left(\mathrm{M}_{\text {highimpact }}=5.60, \mathrm{SEM}=0.245 ; \mathrm{M}_{\text {lowimpact }}=\right.$ 6.00, SEM = 0.18). Moreover, no significant PHASE x IMPACT interaction was observed, $\mathrm{F}_{(1,66)}=0.228, \mathrm{p}=0.635, \eta_{\mathrm{p}}^{2}=0.003$

Finally, the ratings for Item 7 (i.e., felt tension during task performance; see Fig. 2) revealed a significant main effect of PHASE, $F_{(1,66)}=30.800, p<0.001, \eta_{p}{ }^{2}=0.318$, but not of IMPACT, $\mathrm{F}_{(1,66)}=0.248, \mathrm{p}=0.620, \eta_{\mathrm{p}}^{2}=004$. The PHASE $\mathrm{x}$ IMPACT interaction was not significant, $F_{(1,66)}=0.006, p=0.938, \eta_{p}^{2}=0$. Hence, a moderately tensed feeling was reported in both impact groups alike $\left(\mathrm{M}_{\text {highimpact }}=3.94, \mathrm{SEM}=0.31 ; \mathrm{M}_{\text {lowimpact }}=3.79, \mathrm{SEM}=0.24\right)$, especially during task completion $\left(\mathrm{M}_{\text {highimpact }}=5.00, \mathrm{SEM}=0.27 ; \mathrm{M}_{\text {lowimpact }}=4.82, \mathrm{SEM}=0.23\right)$. 


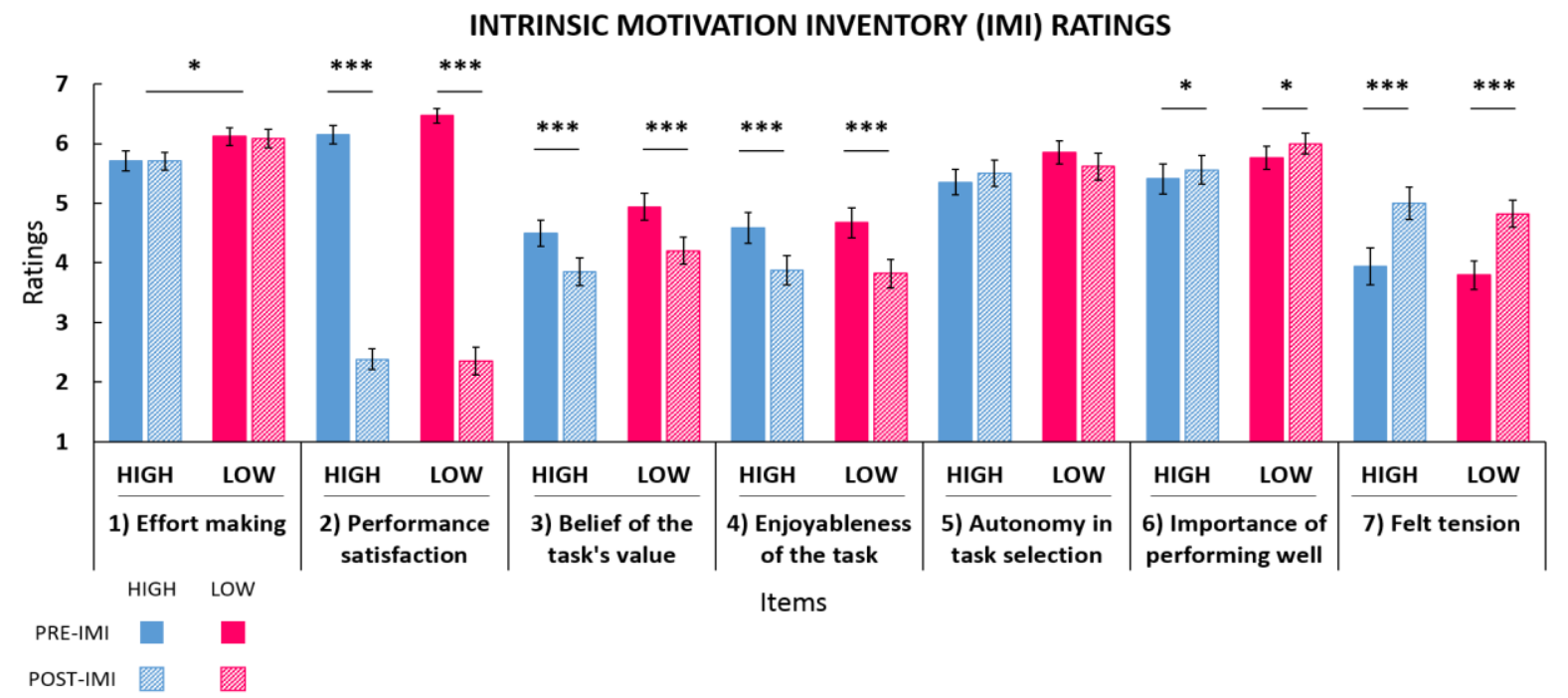

Figure 2. Intrinsic Motivational Inventory (IMI) ratings results. Participants of the two impact groups completed an adapted version of the IMI prior to (pre-IMI) and after (post-IMI) the Go/No Go Task to assess possible differences between them in their experience and motivation towards it. The two groups indicated differential effort exertion (Item 1), with the high impact group reporting less effort than the low impact group. Going from pre- to post-IMI, both groups reported a similar decrease in performance dissatisfaction (Item 2), lowered judgment of the task's value post (Item 3), a more unenjoyable experience of the task (Item 4), slightly increased importance to do well (Item 6), and an increase in tensed feeling (Item 7). Finally, no differences were noted for the experience of autonomy in task selection (Item 5), indicating that autonomy-fostered manipulation was successful. Error bars represent standard errors of the mean $( \pm 1 \mathrm{SEM}) .{ }^{*} \mathrm{p}<0.05 ; * * * \mathrm{p}<0.001$

\subsubsection{Feedback evaluation}

The two impact groups displayed similar evaluation of their actions and liking of the various types of feedback delivered. Table 3 summarizes the subjective ratings. 


\begin{tabular}{|c|c|c|c|c|c|}
\hline \multicolumn{6}{|c|}{ IMPACT } \\
\hline Feedback evaluation probes & $\mathrm{HIGH}$ & LOW & $t$-test & $p$ & $d$ \\
\hline 1. Disliking error making & $78.18( \pm 2.66)$ & $76.97( \pm 4.27)$ & 0.240 & 0.811 & 0.058 \\
\hline 2. Liking correct response & $83.44( \pm 2.37)$ & $85.65( \pm 2.05)$ & -0.705 & 0.484 & -0.171 \\
\hline 3. Disliking receipt of negative feedback & $75.24( \pm 3.50)$ & $77.53( \pm 3.57)$ & -0.459 & 0.648 & -0.111 \\
\hline 4. Liking receipt of positive feedback & $85.09( \pm 2.25)$ & $84.76( \pm 2.20)$ & 0.103 & 0.918 & 0.025 \\
\hline 5. Feedback informativeness & $70.53( \pm 3.53)$ & $69.82( \pm 3.77)$ & 0.137 & 0.892 & 0.033 \\
\hline 6. (Dis)liking of uninformative feedback & $37.62( \pm 3.65)$ & $35.71( \pm 4.09)$ & 0.349 & 0.728 & 0.085 \\
\hline
\end{tabular}

Table 3. Feedback evaluations. The table shows the VAS ratings obtained for feedback evaluation at the subjective level, with the means $( \pm 1$ SEM) reported separately for the two impact groups. The two impact groups did not differ in the extent to which they disliked making errors, liked making correct responses, disliked receiving negative feedback, liked getting positive feedback, perceived the feedback as generally informative of their actions, and disliked the uninformative feedback.

\subsection{Arousal measures}

The log-transformed values of the RMSSD for the HRV analysis revealed a significant fluctuation in the arousal level of the participants throughout the experimental phase (see also Severo et al., 2017). This finding was evident in the significant main effect of PHASE, $F_{(2,132)}$ $=6.232, \mathrm{p}<0.003, \eta p^{2}=0.086$. The two impact groups exhibited heightened RMSSD values going from the baseline recording phase $\left(\mathrm{M}_{\text {highimpact }}=1.54, \mathrm{SEM}=0.05 ; \mathrm{M}_{\text {lowimpact }}=1.60, \mathrm{SEM}\right.$ $=0.04)$ to the task blocks recording phase $\left(\mathrm{M}_{\text {highimpact }}=1.61, \mathrm{SEM}=0.04 ; \mathrm{M}_{\text {lowimpact }}=1.63\right.$, SEM $=0.04)$, suggesting that the arousal level decreased during task execution. The RMSSD values declined later on during the post-task recording $\left(\mathrm{M}_{\text {highimpact }}=1.58, \mathrm{SEM}=0.04 ; \mathrm{M}_{\text {lowimpact }}\right.$ $=1.60, \mathrm{SEM}=0.05)$, suggesting that the arousal level increased. The main effect of IMPACT was not significant, $\mathrm{F}_{(1,66)}=0.426, \mathrm{p}=0.516, \eta \mathrm{p}^{2}=0.006$. Lastly, the PHASE $\mathrm{x}$ IMPACT interaction was not significant either, $\mathrm{F}_{(2,132)}=1.191, \mathrm{p}=0.307, \eta \mathrm{p}^{2}=0.018$. 


\subsection{Behavioral results}

Behavioral indices (i.e., accuracy percentages and RTs, error percentages and RTs, and post-error slowing) revealed that the two impact groups demonstrated comparable performance for the Go/No Go Task. Table 4 summarizes the behavioral results.

\begin{tabular}{|c|c|c|c|c|c|c|}
\hline \multicolumn{2}{|r|}{ PERFORMANCE INDICES } & HIGH IMPACT & LOW IMPACT & $t$-test & $p$ & $d$ \\
\hline \multirow[t]{4}{*}{ 1) } & ACCURACY (\%) & & & & & \\
\hline & - $\quad$ SLOW HITS & $63.90( \pm 1.51)$ & $67.67( \pm 1.70)$ & 1.657 & 0.102 & 0.402 \\
\hline & - $\quad$ FAST HITS & $36.12( \pm 1.51)$ & $32.35( \pm 1.70)$ & -1.661 & 0.101 & -0.403 \\
\hline & - $\quad$ ERROR & $9.86( \pm 0.75)$ & $9.22( \pm 0.71)$ & 0.625 & 0.534 & 0.151 \\
\hline \multirow[t]{6}{*}{ 2) } & REACTION TIME (ms) & & & & & \\
\hline & - SLOW HITS & $310.5( \pm 4.70)$ & $313.7( \pm 5.43)$ & -0.442 & 0.660 & -0.107 \\
\hline & - $\quad$ FAST HITS & $221.9( \pm 3.86)$ & $223.3( \pm 4.17)$ & -0.242 & 0.810 & -0.059 \\
\hline & - $\quad$ ERROR & $246.1( \pm 7.22)$ & $253.9( \pm 6.88)$ & -0.789 & 0.433 & -0.191 \\
\hline & - $\quad$ POST-ERROR & $49.7( \pm 6.39)$ & $39.9( \pm 4.46)$ & 1.256 & 0.214 & 0.305 \\
\hline & - POST-CORRECT & $-4.64( \pm 1.11)$ & $-3.54( \pm 0.91)$ & -0.768 & 0.445 & -0.186 \\
\hline
\end{tabular}

Table 4. Results of performance monitoring behavioral indices. The table summarizes the behavioral results (i.e., percentages and reaction times; means \pm 1 SEM) for the Go/No Go Task. The two impact groups exhibited comparable behavioral performance on the task. More importantly, both groups generated more slow than fast hits, indicating that the intended reward probability (i.e., frequent negative feedback and infrequent positive feedback) was achieved.

\subsection{ERP results}

\subsubsection{FRN}

\subsubsection{FRN: Negative vs. positive feedback ${ }^{4}$}

\footnotetext{
${ }^{4} \mathrm{We}$ also ran an auxiliary analysis to examine possible individual differences in subjective ratings and FRN. In particular, we checked whether FRN reduction was more pronounced for individuals who rated lower Intrinsic Motivation Inventory (IMI) ratings for item 1 (i.e., effort expenditure). This analysis, however, failed to reveal a significant relationship between the ratings and FRN (see supplementary materials for details).
} 
The analysis revealed a highly significant main effect of VALENCE as expected (see Fig. 3), $\mathrm{F}_{(1,66)}=90.921, \mathrm{p}<0.001, \eta_{\mathrm{p}}{ }^{2}=0.579$, indicating a more pronounced $\mathrm{FRN}$ for negative $(\mathrm{M}$ $=2.99 \mu \mathrm{V}, \mathrm{SEM}=0.54)$ than for positive feedback $(\mathrm{M}=7.61 \mu \mathrm{V}, \mathrm{SEM}=0.69)$ at FCz electrode site. Further, this analysis showed a marginally significant main effect of IMPACT, $\mathrm{F}_{(1,66)}=$ $3.509, \mathrm{p}=0.065, \eta_{\mathrm{p}}{ }^{2}=0.050$, with an expected pattern of lower FRN in the high $(\mathrm{M}=6.36 \mu \mathrm{V}$, $\mathrm{SEM}=0.80)$ compared to the low impact group $(\mathrm{M}=4.24 \mu \mathrm{V}, \mathrm{SEM}=0.80)$. Additionally, the VALENCE $x$ IMPACT interaction was not significant, $F_{(1,66)}=2.194, p=0.143, \eta_{p}{ }^{2}=0.032$
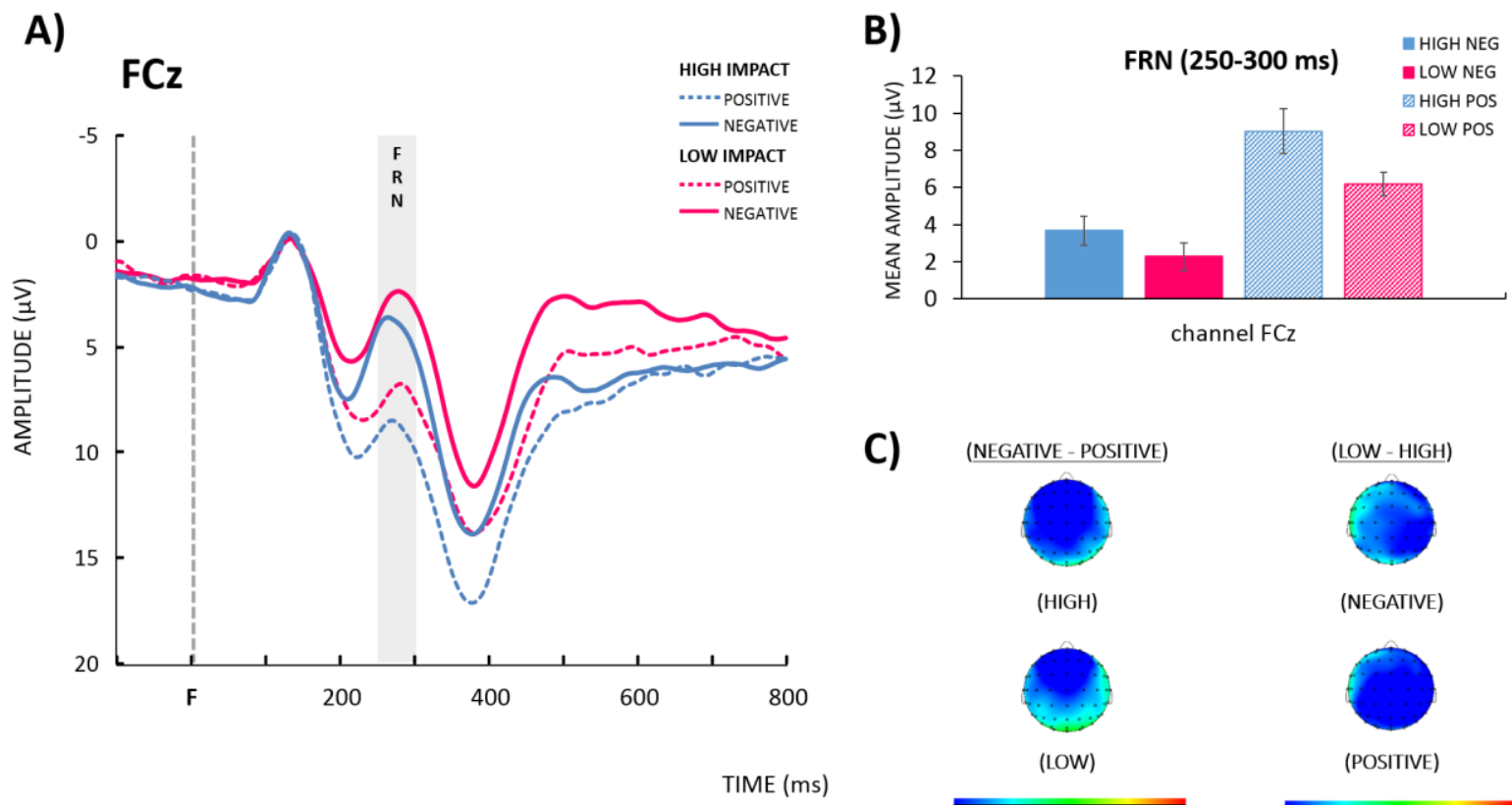

C)

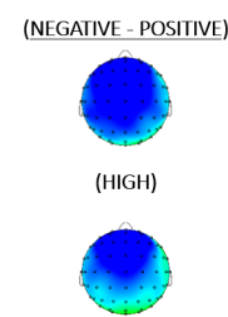

(LOW-HIGH)

(POSITIVE)

Figure 3. Feedback-locked ERP results. (A): Grand average ERP waveforms for channel $\mathrm{FCz}$ for each valence and impact group. Note that $\mathrm{F}$ stands for feedback onset and negativity is plotted upwards. (B) Bar graphs representing mean amplitude $( \pm 1$ SEM) for the FRN extracted in a 250-300 ms time window. (C) The corresponding topographical scalp maps for the FRN.

\subsubsection{FRN: Uninformative feedback}

The analysis showed no significant modulation as a function of IMPACT at FCz channel, $\left(\mathrm{M}_{\text {highimpact }}=5.92 \mu \mathrm{V}, \mathrm{SEM}=1.02 ; \mathrm{M}_{\text {lowimpact }}=4.06 \mu \mathrm{V}, \mathrm{SEM}=0.72\right), t_{(66)}=1.50, \mathrm{p}=0.139, \mathrm{~d}$ $=0.363$. 


\subsubsection{P3}

3.4.2.1 P3: Negative vs. positive feedback

The analysis revealed a significant main effect of VALENCE (see Fig. 4), $\mathrm{F}_{(1,66)}=34.860$, $\mathrm{p}<0.001, \eta_{\mathrm{p}}^{2}=0.346$, showing that positive feedback elicited a larger $\mathrm{P} 3$ component $(\mathrm{M}=$ $11.78 \mu \mathrm{V}, \mathrm{SEM}=0.68)$ relative to negative feedback $(\mathrm{M}=8.75 \mu \mathrm{V}, \mathrm{SEM}=0.59)$ at Pz electrode site. Notably, a significant main effect of $\mathrm{IMPACT}^{5}$ was evident as well, $\mathrm{F}_{(1,66)}=7.692$, $\mathrm{p}=$ $0.007, \eta_{\mathrm{p}}^{2}=0.104$. In line with our main prediction, this effect showed that the P3 component was overall larger in the high $(\mathrm{M}=11.88 \mu \mathrm{V}, \mathrm{SEM}=0.82)$ compared to the low impact group $(\mathrm{M}=8.65 \mu \mathrm{V}, \mathrm{SEM}=0.82)$, regardless of the feedback valence. Moreover, the VALENCE $\mathrm{x}$ IMPACT interaction did not reach significance, $\mathrm{F}_{(1,66)}=1.371, \mathrm{p}=0.246, \eta_{\mathrm{p}}{ }^{2}=0.020$.

\footnotetext{
${ }^{5}$ Because we also found differences in the social anxiety scores (LSAS; Liebowitz, 1987; van Vliet, 1999) between the two impact groups, we ran an additional control analysis to make sure that the P3 modulation was mostly due to the goal impact manipulation. We performed an ANCOVA wherein the LSAS scores were used as a covariate, together with the within-subject factor of VALENCE and the between-subjects factor of IMPACT. This analysis revealed a significant effect of VALENCE, $F_{(1,65)}=7.998, p=0.006, \eta_{p}{ }^{2}=0.110$, and IMPACT, $F_{(1,65)}=8.403, p$ $=0.005, \eta_{\mathrm{p}}{ }^{2}=0.114$. More importantly, no significant effect of LSAS was observed, $F_{(1,65)}=0.768, p=0.384, \eta_{p}{ }^{2}$ $=0.012$. Additionally, none of the interactions reached significance, all $\mathrm{Fs} \leq 1.69$, all $\mathrm{ps} \geq 0.20$. Accordingly, the observed P3 modulation by goal impact could not be attributed to this unexpected group difference in social anxiety.
} 
A)

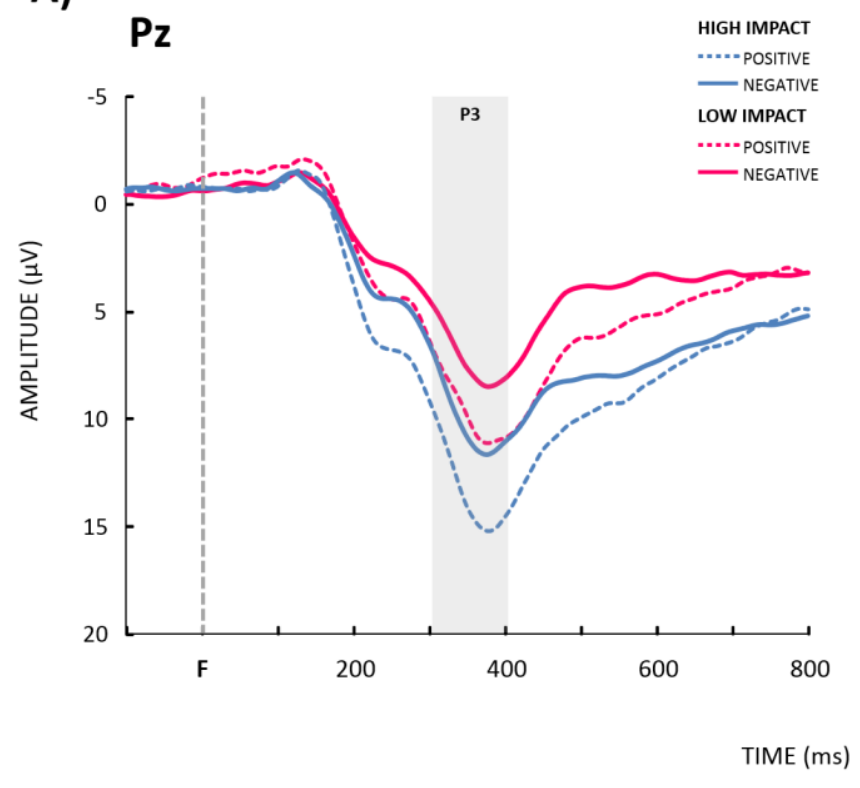

B)

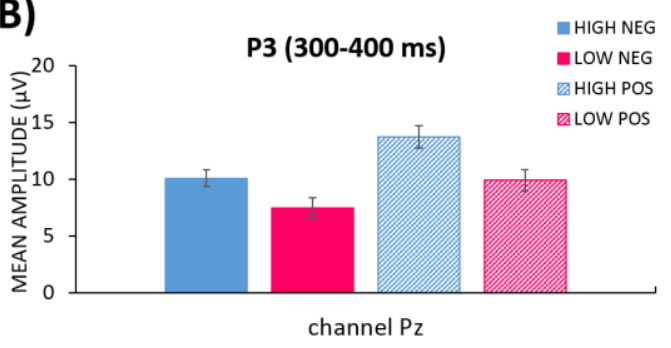

C)

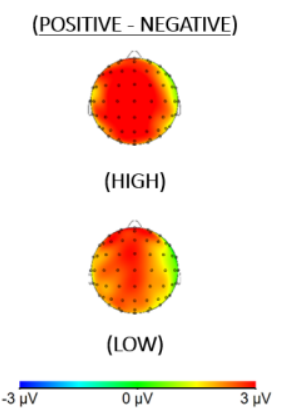

(HIGH-LOW)

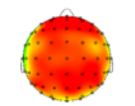

(NEGATIVE)

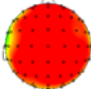

(POSITIVE)

Figure 4. Feedback-locked ERP results. (A): Grand average ERP waveforms for channel Pz for each valence and impact group. Note that F stands for feedback onset and negativity is plotted upwards. (B) Bar graphs representing mean amplitudes ( \pm 1 SEM) for the P3 component extracted in a 300-400 ms time window. (C) The corresponding topographical scalp maps for the P3.

\subsubsection{P3: Uninformative feedback}

The analysis showed only a marginally significant modulation of the P3 as a function of goal impact at Pz channel, $\left(\mathrm{M}_{\text {highimpact }}=14.20 \mu \mathrm{V}, \mathrm{SEM}=1.11 ; \mathrm{M}_{\text {lowimpact }}=11.27 \mu \mathrm{V}, \mathrm{SEM}=\right.$ $1.20), t_{(66)}=1.791, \mathrm{p}=0.078, \mathrm{~d}=0.434$.

\subsubsection{ERN}

The analysis revealed a significant main effect of RESPONSE, $\mathrm{F}_{(1,66)}=79.865, \mathrm{p}<0.001$, $\eta_{\mathrm{p}}{ }^{2}=0.548$, showing that this component was more negative for errors (ERN; $\mathrm{M}=-2.45 \mu \mathrm{V}$, $\mathrm{SEM}=0.82)$ than hits $(\mathrm{CRN} ; \mathrm{M}=3.09 \mu \mathrm{V}, \mathrm{SEM}=0.71)$ at $\mathrm{FCz}$ electrode site (see supplementary materials for a figure showing ERN/CRN waveforms). The main effect of IMPACT did not reach significance, $F_{(1,66)}=0.750, p=0.390, \eta_{p}{ }^{2}=0.011$, although the negativity was smaller in the high $(\mathrm{M}=0.93 \mu \mathrm{V}, \mathrm{SEM}=0.99)$ compared to the low impact 
group $(\mathrm{M}=-0.29 \mu \mathrm{V}, \mathrm{SEM}=0.99)$. The RESPONSE $\mathrm{x}$ IMPACT interaction was not significant, $\mathrm{F}_{(1,66)}=1.652, \mathrm{p}=0.203, \eta_{\mathrm{p}}^{2}=0.024$

\subsubsection{Temporospatial PCA factors}

Four of the total 19 windowed factors were recognized to closely correspond to the FRN and P3 components in terms of time course and scalp distribution (see Table 5 and Figure 5).

\begin{tabular}{|c|c|c|c|c|}
\hline PCA Factor & $\begin{array}{c}\text { Associated ERP } \\
\text { component }\end{array}$ & Peak Latency (ms) & Peak Channel & Variance \\
explained (\%) \\
\hline TF3SF1 & FRN & 273 & FCz & 8.5 \\
\hline TF4SF1 & P3 & 354 & FCz & 0.6 \\
\hline TF4SF2 & P3 & 354 & POz & 0.9 \\
\hline TF8SF1 & P3 & 416 & FCz & \\
\hline
\end{tabular}

Table 5. Temporospatial PCA factors. The table presents the four temporospatial factors selected after PCA for data analysis. Note that SF stands for spatial factor and TF for temporal factor.

\subsubsection{PCA factor corresponding to FRN (TF3SF1)}

The amplitude of PCA factor TF3SF1 had a peak latency at $273 \mathrm{~ms}$ and was most prominent at the fronto-central area, reaching its maximum at $\mathrm{FCz}$ (see Fig. 5A). This factor closely corresponds to the FRN component. The robust ANOVA revealed that the main effect of VALENCE was significant (corrected), $\mathrm{T}_{\mathrm{WJ}} / \mathrm{c}(1.0,56.9)=81.01, \mathrm{p}<0.00000001$, showing more negativity of the factor for negative $(\mathrm{M}=2.98 \mu \mathrm{V})$ than for positive feedback $(\mathrm{M}=7.01$ $\mu \mathrm{V})$. The main effect of IMPACT, on the other hand, only reached one-tailed significance (uncorrected), $\mathrm{T}_{\mathrm{WJ}} / \mathrm{c}(1.0,54.4)=2.83, \mathrm{p}=0.05$. This result revealed that the factor was more negative in the low impact $(\mathrm{M}=3.89 \mu \mathrm{V})$ than the high impact group $(\mathrm{M}=6.10 \mu \mathrm{V})$. No significant VALENCE x IMPACT interaction was found, $\mathrm{T}_{\mathrm{WJ}} / \mathrm{c}(1.0,56.9)=0.41, \mathrm{p}=0.54$. 


\subsubsection{PCA factor corresponding to P3 (TF4SF1)}

The amplitude of PCA factor TF4SF1 had a peak latency at $353 \mathrm{~ms}$ and was most prominent at the fronto-central area, with its maximum at $\mathrm{FCz}$ (see Fig. 5B). The robust ANOVA showed a significant main effect of VALENCE (corrected), $\mathrm{T}_{\mathrm{WJt}} / \mathrm{c}(1.0,56.7)=7.67$, $\mathrm{p}=0.0070$, suggesting more positivity of the factor for positive $(\mathrm{M}=8.60 \mu \mathrm{V})$ than for negative feedback $(\mathrm{M}=7.22 \mu \mathrm{V})$. The main effect of IMPACT only reached one-tailed significance (uncorrected), $\mathrm{T}_{\mathrm{WJ}} / \mathrm{c}(1.0,61.6)=3.98, \mathrm{p}=0.026$, showing more positivity of the factor in the high impact $(\mathrm{M}=9.00 \mu \mathrm{V})$ than in the low impact group $(6.83 \mu \mathrm{V})$. The VALENCE $\mathrm{x}$ IMPACT interaction failed to reveal a significant effect, $\mathrm{T}_{\mathrm{WJt}} / \mathrm{c}(1.0,56.7)=0.44, \mathrm{p}=0.51$.

\subsubsection{PCA factor corresponding to P3 (TF4SF2)}

The amplitude of PCA factor TF4SF2 had a peak latency at $353 \mathrm{~ms}$, but was most prominent at the parietal area, reaching its maximum at $\mathrm{POz}$ (see Fig. 5C). This factor closely corresponds to the P3 component. The robust ANOVA indicated a significant main effect of VALENCE (corrected), T ${ }_{\mathrm{WJ}} / \mathrm{c}(1.0,61.0)=24.50, \mathrm{p}<0.00000001$. This effect suggested more positivity of the factor for positive $(\mathrm{M}=1.70 \mu \mathrm{V})$ than for negative feedback $(\mathrm{M}=0.88)$. Neither the main effect of IMPACT, $\mathrm{T}_{\mathrm{WJ}} / \mathrm{c}(1.0,56.2)=0.01, \mathrm{p}=0.94$, nor the VALENCE $\mathrm{x}$ IMPACT interaction, $\mathrm{T}_{\mathrm{WJt}} / \mathrm{c}(1.0,61.0)=1.06, \mathrm{p}=0.30$, reached significance.

\subsubsection{PCA factor corresponding to P3 (TF8SF1)}

The amplitude of PCA factor TF8SF1 had a peak latency at $416 \mathrm{~ms}$ and was most prominent at the fronto-central area, with its maximum at $\mathrm{FCz}$ (see Fig. 5D). The robust ANOVA revealed that the main effect of VALENCE reached significance (uncorrected), $\mathrm{T}_{\mathrm{WJ}} / \mathrm{c}(1.0,61.3)=4.89, \mathrm{p}=0.031$. This effect suggested more positivity of the factor for positive $(\mathrm{M}=2.30 \mu \mathrm{V})$ than for negative feedback $(\mathrm{M}=1.60)$. Both the main effect of IMPACT, $\mathrm{T}_{\mathrm{WJ}} / \mathrm{c}(1.0,54.8)=1.05, \mathrm{p}=0.31$, and the VALENCE $\mathrm{x}$ IMPACT interaction, $\mathrm{T}_{\mathrm{WJt}} / \mathrm{c}(1.0,61.3)$ $=0.79, \mathrm{p}=0.37$, did not reach significance. 


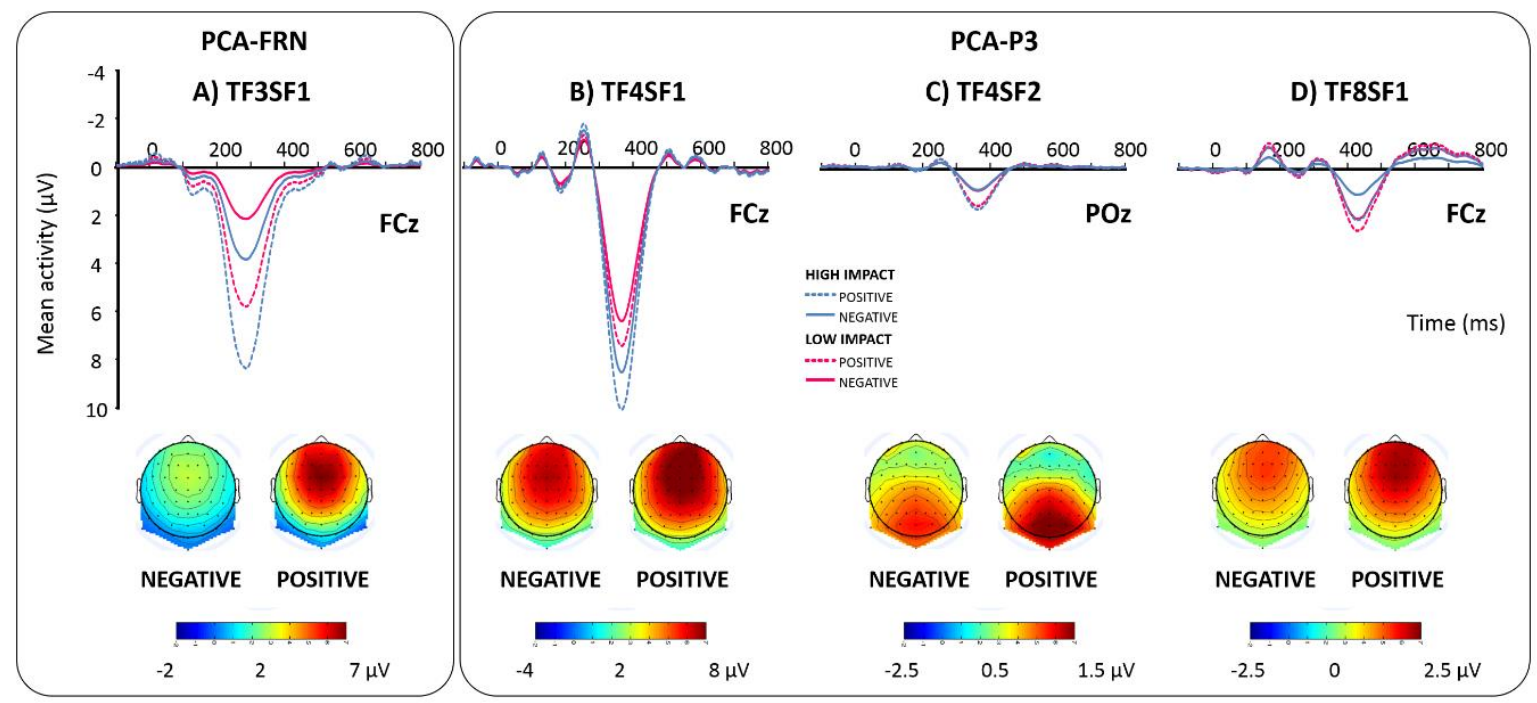

Figure 5. Temporospatial factors obtained after PCA and accounting for FRN and P3, with the corresponding scalp topographies. The figure shows the amplitudes of the PCA factors that closely corresponded to the FRN and P3 components: (A) Factor TF3SF1, corresponding to the FRN, was most prominent at the fronto-central area and had a peak latency at $273 \mathrm{~ms}$. (B) Factor TF4SF1 was most prominent at the fronto-central area and had a peak latency at $353 \mathrm{~ms}$. (C) Factor TF4SF2 was most prominent at the parietal area and had a peak latency at $353 \mathrm{~ms}$. (D) Factor TF8SF1 was most prominent at the fronto-central area and had a peak latency at $416 \mathrm{~ms}$. All three factors corresponded to the $\mathrm{P} 3$ component. Note that negativity is plotted upwards. Topographical maps are shown separately for the positive and negative feedback conditions.

\section{Discussion}

This study aimed to replicate and extend the modulation in feedback-based PM (captured at FRN and P3 levels) as a function of goal impact found in our previous work (Severo et al., 2017). More specifically, we further scrutinized the observed overall reduction in the FRN and enhanced P3 in light of our tentatively proposed self-protection account. In an effort to attain a clearer goal impact effect, a simpler goal impact manipulation (achieved by means of the alleged diagnosticity of the Go/No Go Task) was embedded in a between-subjects design experiment. Moreover, we supplemented the standard peak analysis of the feedback-locked ERP data with a PCA in order to ascertain that the FRN and P3 showed dissociable electrophysiological properties and were both influenced by the goal impact manipulation, yet in opposite directions. Our new findings largely resemble what we previously found (Severo et al., 2017): Goal impact reliably influenced feedback-based PM at the ERP level, without 
differences in arousal or task involvement between the two impact groups. This ERP modulation, however, was mostly captured by the P3 component (being larger for high than low impact, irrespective of valence), whereas the preceding FRN showed only a marginally significant effect that went in the same direction as before (Severo et al., 2017). The observed enhanced P3 component in the high impact group seems to suggest that participants in this group assigned a higher motivational significance to the feedback compared to the low impact group. Hereafter, we discuss the possible theoretical implications of these new results.

Reward probability (i.e., frequent negative vs. infrequent positive feedback) was successfully kept constant between the two impact groups in this study, as evident in the behavioral performance of the participants (see Table 2; see also Severo et al., 2017; Walentowska et al., 2016, 2018). This pre-requisite was important as comparing the groups at the ERP level hinged upon equivalent task involvement and performance. Additionally, we found a balanced arousal level between the two groups when assessing the HRV, in accordance with our previous study (Severo et al., 2017). This outcome confirmed that our goal impact manipulation did not merely influence arousal. Furthermore, our results showed a decrease in the arousal level during task completion relative to the baseline period for the two groups alike, as revealed by the increasing RMSSD (the index used for HRV). This expected outcome could be attributed to the necessity to modulate cardiac activity to effectively execute the inhibitory demands of the Go/No Go Task (being a cognitive control task). Dominant models linking HRV to self-control assume that better ability to inhibit impulses is manifested in greater HRV (Baumeister et al., 2007; Porges, 2001, 2007; Thayer et al., 2009).

Our subjective rating probes revealed mostly similar but also some differing reactions between the participants in the two goal impact conditions. First, our attempt to control for an autonomy-fostered task selection (Legault \& Inzlicht, 2013) between the groups seemed successful since the ratings for this IMI item remained the same prior to and after the task. This 
shows that autonomy, identified as a fundamental need (e.g., Ryan \& Deci, 2000), was balanced between the two groups, and remained stable throughout the experimental session. Second, both groups seemed to experience the task as unpleasant overall. The IMI ratings showed that both groups felt dissatisfied with their performance of the task, found it unenjoyable, reported tension while doing it, and judged it to have low value. In the same vein, the ratings for the various types of feedback did not systematically vary between the two groups. Taken together, these results therefore suggest that a general impression of unsatisfactory performance and frustration emerged from participants in both groups. Earlier studies (see Berglas \& Jones; 1978; Frankel \& Snyder, 1978) have documented the tendency of individuals to reduce effort as a means to safeguard self-esteem from threats of subsequent failure. In line with this, the high impact group already expected to invest less effort (as revealed by the pre-IMI) in contrast to the low impact group. This might be an anticipatory defensive strategy, which Pyszczynski and Greenberg (1983) observed to occur when failure is probable. It is possible that the high impact group activated such a defensive stance after completing the practice block in which they had brief experience with the task (leading to a majority of negative feedback) and likely received a worse-than-expected score.

Moreover, we found partial evidence supporting the notion that the high impact group engaged in a self-protection strategy or attempted to downplay the threatening information conveyed by the feedback. The IMI item on effort exertion generated differences between the two groups, with the high impact group reporting less effort than the low impact group. The different effort ratings were not reflected in different ratings of the importance of performing well, however, and they were in striking contrast with the actual behavioral indices demonstrating that the high impact group did not perform worse or slower than the low impact group. The reported diminished effort investment in the high impact group may be an indication of an attribution bias, in this case, the attribution of failure to unstable factors (like effort 
expenditure) as opposed to stable factors (such as ability; Pyszczynski \& Greenberg, 1983). This bias may serve to protect or to enhance the self, as documented in the literature on psychological self-defense (von Hippel et al., 2005; Koole \& Kuhl, 2003; Sedikides \& Gregg, 2003; Sedikides \& Koole, 2004).

More importantly, the ERP results replicated our previous finding (Severo et al., 2017) showing that goal impact reliably influenced feedback processing during PM, expressed by a larger P3 component in the high compared to the low impact group. While current models of PM assume that goals and context play an important role in action evaluation and flexible adaptation (Ullsperger et al., 2014b), this role has rarely been examined empirically in previous studies however. Combined together, our ERP findings therefore add to our understanding of contextual modulations of PM brain processes, here with a focus on goal relevance (Gentsch et al., 2013; Osinsky et al., 2017; Severo et al., 2017; Walentowska et al., 2016, 2018). Moreover, the goal impact effect found at the P3 level in this and our previous study can be interpreted using a hierarchical model of PM (Badre, 2008), as proposed by Walentowska et al. (2016; see also Severo et al., 2017; but see Holroyd \& Yeung, 2012). This model assumes that besides valence and expectedness, goal relevance also contributes to shape PM. As our ERP results show, it can enhance PM at the P3 level (as well as reduce the preceding FRN), yet without altering valence or expectedness, because it likely operates at a superordinate level during feedback processing compared to these two factors (Severo et al., 2017; Walentowska et al., 2016). In comparison and similarly to our previous study (Severo et al., 2017), internal PM (at the ERN/CRN level) remained unaffected by goal impact, suggesting that this variable does not influence this process uniformly, but instead, it alters the processing of evaluative feedback, selectively.

A larger P3 in the high compared to the low impact condition informs indirectly about the functional meaning of this mid-latency ERP component, and more specifically, its involvement 
in the processing of the motivational significance of the feedback during PM. First, our results showed that the positive feedback elicited a larger amplitude of P3 than the negative feedback, irrespective of goal impact. This finding is consistent with studies reporting larger P3 for gains than for losses (Bellebaum \& Daum, 2008; Bellebaum et al., 2010; Gu et al., 2011; Hajcak et al., 2007; Kreussel et al., 2012; Polezzi et al., 2010; Toyomaki \& Murohashi, 2005; Wu \& Zhou, 2009; Zhou et al., 2010). Second, our results also demonstrated that the feedback in the high impact group showed an overall larger P3 relative to the low impact group, as if the former assigned a greater motivational significance to the feedback than the latter, irrespective of its valence. This assignment might be a manifestation of enhanced attention allocation to information with high goal impact in the high impact group. An alternative interpretation is that the increased P3 in the high impact group reflects stronger updating of this information (Donchin \& Coles, 1998; Polich, 2007), in line with the adaptive gain theory, which posits that coding of motivationally relevant events in the P3 component serves to potentiate and optimize further actions (Nieuwenhuis et al., 2005; Aston-Jones \& Cohen, 2005a, 2005b). It is worth noting in this context that Ullsperger and colleagues $(2013,2014 b)$ have postulated that the P3a reflects orientation to potentially action-relevant information, while its motivational meaning is processed at the later $\mathrm{P} 3 \mathrm{~b}$ level that shares many similarities with the $\mathrm{P} 3$ component elicited in the current study. More strongly updating the motivational meaning of the action may have been adaptive for the high impact group to end an ongoing trial (despite initially withdrawing from the evaluative stage at the FRN level due to self-protection) and to immediately use this action value to guide future decisions in the subsequent trials. The delayed P3 amplitude elicited by the uninformative feedback may also provide support, albeit indirectly, to this idea. Intriguingly, whereas this feedback type was infrequent (oddball), it seemed to be updated at a later time in comparison to the processing of positive and negative feedback. This suggests that when feedback did not carry any valuable information regarding action value, it took longer to 
update this event than when a clear value could readily be extracted based on it. Interestingly, in both groups, this uninformative feedback also elicited an FRN component prior to the delayed P3, resembling that elicited for the negative feedback, similar to what Gu et al. (2017) previously reported.

Although our ERP results confirmed our hypothesis for the P3, we only found a marginally significant and modest amplitude reduction of the preceding FRN when goal impact was increased. However and importantly, the FRN component was numerically less negative in the high than in the low impact group, as we had hypothesized based on our previous study (Severo et al., 2017). Tentatively, this mild modulation of the FRN with the goal impact manipulation chosen might be due to the use of a between-subjects design in the present case, which may have introduced a larger inter-individual (and inter-group) variability compared to our previous study. This larger variability in turn may have obscured a systematic modulation of the FRN by goal impact. We note however that this interpretation fails to explain the significant modulation found at the P3 level satisfactorily given that inter-individual variability had likely comparable deleterious effects on these two successive ERP components (FRN and P3). Alternatively, removing social comparison from the goal impact manipulation as we did here, may have somehow weakened its systematic modulatory effect on the processing of evaluative feedback at the FRN level as we previously found (Severo et al., 2017). Hence, in the current study where we explicitly used a between-subjects design to achieve a more specific manipulation of goal impact, it is possible that it was eventually less potent in terms of self-protection activation in order to reliably influence PM at the FRN level, compared to that of the previous study. Future ERP studies where different manipulations of goal impact are performed and compared with each other are needed to address this question at the empirical level. Notwithstanding these caveats, additional analyses of the ERP data allowed us to rule out the possibility that the pattern of ERP results found (i.e., mild lower FRN but increased P3 with high goal impact) was caused 
by a general interfering effect that would distort feedback processing at the ERP level, for example. First, as already briefly discussed here above, both groups showed comparable FRN and delayed P3 for the uninformative feedback, suggesting that this unexpected event was processed equally strongly in both groups. Second, and more importantly, we used a stringent PCA confirming that the FRN and P3, although showing some spatial and temporal overlap (Bernat et al., 2008), could be disentangled from each other. Crucially, the disentanglement of the ERP components revealed the opposing effects of goal impact, with a smaller FRN but larger P3 with high goal impact. These complementary results are important because they not only corroborate the outcome of the standard ERP data analysis, but also allow us to ascertain that these two successive ERP components reflected partly separate evaluative processes during feedback processing (Miltner et al., 1997; Bernat et al., 2008; Ullsperger et al., 2014a, 2014b).

A few limitations warrant comment. First, despite our efforts to manipulate goal impact in a purer way through the use of a simpler design, we cannot rule out the possibility that the manipulation was weak to elicit systematic modulation at the FRN level, as briefly discussed here above. In future studies, stronger manipulations of goal impact seem therefore desirable. In relation to this, it may also be advantageous to consider the impact of other goals than the goal to uphold self-esteem. Doing so could establish whether the effects also generalize to other goals. A good place to start may be to study the impact of goals pertaining to social status, as some studies have demonstrated FRN variations when status-related differences were made salient (Boksem et al., 2012) and individuals were outperformed by peers (Boksem et al., 2010). It might be interesting to examine whether feedback-based PM would be diminished (or enhanced) when an initially hard-earned high social status is at stake.

A second limitation is that while participants in both impact groups were carefully matched in terms of their prior self-esteem (measured via the RSES; Franck et al., 2008; Rosenberg, 1965), we did not systematically consider individual differences along this or other trait 
variables. Indeed, we did not pre-screen and identify participants with high vs. low self-esteem. Individual differences in self-esteem might have some bearing on the complex relationship between goal impact and the FRN and P3 components. For instance, several studies have shown that high self-esteem can buffer against the effects of negative feedback and other unpleasant events (Brown, 2010; Brown \& Marshall, 2001, 2006). Future studies might be set up to further explore whether self-esteem can modulate feedback-based PM when different levels of goal impact are systematically compared with each other.

Finally, it remains to be studied whether the pattern of results obtained here with our goal impact manipulation (P3 and FRN) would replicate in an experimental setting in which positive feedback is more frequent than negative feedback. Previous work from our lab (see Experiment 3 of Walentowska et al., 2018) has empirically validated a method with a more lenient response deadline that effectively generates frequent positive feedback (2/3) and infrequent negative feedback (1/3) using the same Go/No Go task. A drawback of this procedure, however, is that the FRN component less clearly discriminates negative from positive outcomes. Accordingly, even though it may be challenging to record a clear FRN when positive feedback on task performance dominates throughout the experimental session, it appears however important in future studies to examine the boundaries of the goal impact effect reported here by systematically varying reward probability across conditions.

In conclusion, the present study adds to our understanding of PM brain processes and the extent to which they are malleable by goal impact beyond valence and expectedness. More specifically, increasing goal impact was associated with a larger feedback-based P3 ERP component during PM, irrespective of valence. This effect was interpreted as indicating that a higher motivational significance was likely attributed to performance feedback in the high compared to the low impact condition, even though some form of self-protection could be present in the former condition, as the FRN results indirectly suggest. Alternatively, because 
the P3 component was previously linked to the updating of action value during PM (Ullsperger, 2017; Ullsperger et al., 2014b), enhancing goal impact may facilitate action updating. Both interpretations agree with the general idea that PM brain processes are best conceived of as not solely operating on the basis of motor cues, but that they are context dependent and influenced by the concurrent demands of recently activated goals.

\section{Acknowledgements}

This work is supported by a research grant (number 3G024716) from the FWO (Research

Foundation - Flanders) awarded to Gilles Pourtois and Agnes Moors.

\section{References}

Aarts, K., \& Pourtois, G. (2010). Anxiety not only increases, but also alters early errormonitoring functions. Cognitive, Affective and Behavioral Neuroscience, 10(4), 479492. https://doi.org/10.3758/CABN.10.4.479

Aarts, K., \& Pourtois, G. (2012). Anxiety disrupts the evaluative component of performance monitoring: An ERP study. Neuropsychologia, 50(7), 1286-1296. https://doi.org/10.1016/j.neuropsychologia.2012.02.012

Alicke, M. D., \& Sedikides, C. (2011). Self-enhancement and self-protection: Historical overview and conceptual framework. In M. D. Alicke, \& C. Sedikides (Eds.). Handbook of self-enhancement and self-protection. New York: Guilford Press.

Allain, S., Carbonnell, L., Falkenstein, M., Burle, B., \& Vidal, F. (2004). The modulation of the Ne-like wave on correct responses foreshadows errors. Neuroscience Letters, 372(12), 161-166. http://dx.doi.org/10.1016/j.neulet.2004.09.036

Appelhans, B. M., \& Luecken, L. J. (2006). Heart rate variability as an index of regulated emotional responding. Review of General Psychology, 10(3), 229-240. http://dx.doi.org/10.1037/1089-2680.10.3.229

Aston-Jones, G. and Cohen, J.D. (2005a). Adaptive gain and the role of the locus coeruleusnorepinephrine system in optimal performance. Journal of Comparative Neurology, 493, 99-110. https://doi.org/10.1002/cne.20723

Aston-Jones, G., \& Cohen, J. D. (2005b). An integrative theory of locus coeruleusnorepinephrine function: Adaptive Gain and Optimal Performance. Annual Review of Neuroscience, 28(1), 403-450. https://doi.org/10.1146/annurev.neuro.28.061604.135709 
Atkinson, J. W., \& Feather, N. T. (Eds.). (1966). A theory of achievement motivation. New York, NY: Wiley.

Badre, D. (2008). Cognitive control, hierarchy, and the rostro-caudal organization of the frontal lobes. Trends in Cognitive Sciences, 12(5), 193-200.

https://doi.org/10.1016/j.tics.2008.02.004

Baumeister, R. F., Campbell, J. D., Krueger, J. I., \& Vohs, K. D. (2003). Does high selfesteem cause better performance, interpersonal success, happiness or healthier lifestyle? Psychological Science in the Public Interest, 4(1), 1-44. http://dx.doi.org/10.1111/15291006.01431.

Baumeister, R. F.,Vohs, K. D., \& Tice, D. M. (2007).The strength model of self-control. Current Directions in Psychological Science, 16(6),351355.http://dx.doi.org/10.1111/j.1467-8721.2007.00534.x

Bellebaum, C., \& Daum, I. (2008). Learning-related changes in reward expectancy are reflected in the feedback-related negativity. European Journal of Neuroscience, 27(7), 1823-1835. https://doi.org/10.1111/j.1460-9568.2008.06138.x

Bellebaum, C., Polezzi, D., \& Daum, I. (2010). It is less than you expected: The feedbackrelated negativity reflects violations of reward magnitude expectations.

Neuropsychologia, 48(11), 3343-3350.

https://doi.org/10.1016/j.neuropsychologia.2010.07.023

Bennett, D., Bode, S., Brydevall, M., Warren, H., \& Murawski, C. (2016). Intrinsic Valuation of Information in Decision Making under Uncertainty. PLoS Computational Biology, 12(7), 1-21. https://doi.org/10.1371/journal.pcbi.1005020

Berglas, S., \& Jones, E. E. (1978). Drug choice as a self-handicapping strategy in response to non-contingent success. Journal of Personality and Social Psychology, 36, 405-417. http://dx.doi.org/10.1037/0022-3514.36.4.405

Bernat, E. M., Nelson, L. D., Holroyd, C. B., Gehring, W. J., Patrick, C. J. (2008). Separating cognitive processes with principal component analysis of EEG time-frequency distributions. Proc. SPIE 7074, Advanced Signal Processing Algorithms, Architectures, and Implementations XVIII, 70740S. https://doi.org/10.1117/12.801362.

Bismark, A. W., Hajcak, G., Whitworth, N. M., \& Allen, J. J. B. (2013). The role of outcome expectations in the generation of the feedback-related negativity. Psychophysiology, 50(2), 125-133. https://doi.org/10.1111/j.1469-8986.2012.01490.x

Boksem, M. A. S., Kostermans, E., \& De Cremer, D. (2011). Failing where others have succeeded: Medial Frontal Negativity tracks failure in a social context. Psychophysiology, 48(7), 973-979. https://doi.org/10.1111/j.1469-8986.2010.01163.x 
Boksem, M. A. S., Kostermans, E., Milivojevic, B., \& De cremer, D. (2012). Social status determines how we monitor and evaluate our performance. Social Cognitive and Affective Neuroscience, 7(3), 304-313. https://doi.org/10.1093/scan/nsr010

Brown, J. D. (2010). High self-esteem buffers negative feedback: Once more with feeling. Cognition and Emotion, 24(8), 1389-1404. https://doi.org/10.1080/02699930903504405

Brown, J. D., \& Marshall, M. A. (2001). Self-esteem and emotion: Some thoughts about feelings. Personality and Social Psychology Bulletin, 27(5), 575-584. https://doi.org/10.1177/0146167201275006

Brown, J. D., \& Marshall, M. A. (2006). The three faces of self-esteem. In M. Kernis (Ed.), Self-esteem: Issues and Answers (pp. 4-9). New York: Psychology Press.

Campbell, J. I. D. \& Thompson, V. A. T. (2012). MorePower 6.0 for ANOVA with relational confidence intervals and Bayesian analysis. Behavior Research Methods, 44, 1255-1265. http://dx.doi.org/10.3758/s13428-012-0186-0

Carver, C. S., \& White, T. L. (1994). Behavioral inhibition, behavioral activation, and affective responses to impending reward and punishment: The BIS/BAS scales, 67(2), 319-333. Journal of Personality and Social Psychology. http://dx.doi.org/10.1037/00223514.67.2.319

Cavanagh, J. F., Gründler, T. O. J., Frank, M. J., \& Allen, J. J. B. (2010). Altered cingulate sub-region activation accounts for task-related dissociation in ERN amplitude as a function of obsessive-compulsive symptoms. Neuropsychologia, 48(7), 2098-2109. https://doi.org/10.1016/j.neuropsychologia.2010.03.031

Danielmeier, C., Eichele, T., Forstmann, B. U., Tittgemeyer, M., \& Ullsperger, M. (2011). Posterior Medial Frontal Cortex Activity Predicts Post-Error Adaptations in TaskRelated Visual and Motor Areas. Journal of Neuroscience, 31(5), 1780-1789. https://doi.org/10.1523/JNEUROSCI.4299-10.2011

Danielmeier, C., \& Ullsperger, M. (2011). Post-error adjustments. Frontiers in Psychology, 2, 1-10. https://doi.org/10.3389/fpsyg.2011.00233

Deci, E. L., Eghrari, H., Patrick, B. C., \& Leone, D. (1994). Facilitating internalization: The self-determination theory perspective. Journal of Personality, 62, 119-142. http://dx.doi.org/10.1111/j.1467-6494.1994.tb00797.x

Desmedt, J. E., Debecker, J., \& Manil, J. (1965). Demonstration of a cerebral electric sign associated with the detection by the subject of a tactile sensorial stimulus. The analysis of cerebral evoked potentials derived from the scalp with the aid of numerical ordinates. Bulletin De l'Académie Royale De Médecine De Belgique, 5, 887-936. 
Dhar, M., \& Pourtois, G. (2011). Early error detection is generic, but subsequent adaption to errors is not: Evidence from ERPs. Neuropsychologia, 49, 1236-1245. http://dx.doi. org/10.1016/j.neuropsychologia.2011.01.006

Dhar, M., Wiersema, J. R., \& Pourtois, G. (2011). Cascade of neural events leading from error commission to subsequent awareness revealed using EEG source imaging. PLoS One, 6. http://dx.doi.org/10.1371/journal.pone.0019578

Dien, J. (2010a). The ERP PCA Toolkit: An open source program for advanced statistical analysis of event-related potential data. Journal of Neuroscience Methods, 187, 138-145. https://doi.org/10.1016/j.jneumeth.2009.12.009

Dien, J. (2010b). Evaluating two-step PCA of ERP Data with Geomin, Infomax, Oblimin, Promax, And Varimax Rotations. Psychophysiology, 47(1), 170-183. https://doi.org/10.1111/j.1469-8986.2009.00885.x

Dien, J., \& Santuzzi, A. M. (2005). Application of repeated measures ANOVA to highdensity ERP datasets: A review and tutorial. In T. Handy (Ed.), Event-Related Potentials: A Methods Handbook (pp. 57-82). Cambridge, Mass: MIT Press.

Donchin, E., \& Coles, M. G. (1998). Context updating and the P300. Behavioral and Brain Sciences, 21, 152-154. doi: 10.1017/ S0140525X98230950

Donkers, F. C. L., Nieuwenhuis, S., \& Van Boxtel, G. J. M. (2005). Mediofrontal negativities in the absence of responding. Cognitive Brain Research, 25(3), 777-787. https://doi.org/10.1016/j.cogbrainres.2005.09.007

Eitam, B., \& Higgins, E. T. (2010). Motivation in mental accessibility: Relevance of a representation (ROAR) as a new framework. Social and Personality Psychology Compass, 4, 951-967. doi: 10.1111/j.1751- 9004.2010.00309.x

Falkenstein, M., Hohnsbein, J., \& Blanke, L. (1990). Effects of errors in choice reaction tasks on the ERP under focused and divided attention. In C. H. Brunia, A. W. Gaillard, \& A. Kok (Eds.). Psychophysiological Brain Research (pp. 192-195). Tilburg, The Netherlands: Tilburg UP.

Falkenstein, M., Hoormann, J., Christ, S., \& Hohnsbein, J. (2000). ERP components on reaction errors and their functional significance: A tutorial. Biological Psychology, 51(23), 87-107. https://doi.org/10.1016/S0301-0511(99)00031-9

Ferdinand, N. K., Mecklinger, A., Kray, J., \& Gehring, W. J. (2012). The processing of unexpected positive response outcomes in the mediofrontal cortex. The Journal of Neuroscience, 32(35), 12087-12092. https://doi.org/10.1523/JNEUROSCI.1410-12.2012 
Fischer, A., \& Ullsperger, M. (2013). Real and fictive outcomes are processed differently but converge on a common adaptive mechanism. Neuron, 79(6), 1243-1255. https://doi.org/10.1016/j.neuron.2013.07.006

Folk, C. L., \& Remington, R. W. (2008). Bottom-up priming of top-down attentional control settings. Visual Cognition, 16, 215-231. doi: 10.1080/13506280701458804

Franck, E., De Raedt, R., Barbez, C., \& Rosseel, Y. (2008). Psychometric properties of the dutch rosenberg self-esteem scale. Psychologica Belgica, 48, 25-35. http://dx.doi.org/ $10.5334 / \mathrm{pb}-48-1-25$

Frankel, A., \& Snyder, M. L. (1978). Poor performance following unsolvable problems: Learned helplessness or egotism? Journal of Personality and Social Psychology, 36, 1415-1423. http://dx.doi.org/10.1037/0022-3514.36.12.1415

Franken, I. H. A. (2002). Behavioral approach system (BAS) sensitivity predicts alcohol craving. Personality and Individual Differences, 32, 349-355. http://dx.doi.org/10. 1016/S0191-8869(01)00030-7

Frijda, N. H. (1986). The emotions. New York, NY: Cambridge University Press.

Gehring, W. J., Gross, B., Coles, M. G. H., Meyer, D. E., \& Donchin, E. (1993). A neural system for error detection and compensation. Psychological Science, 4, 385-390. http://dx.doi.org/10.1111/j.1467-9280.1993.tb00586.x

Gehring, W. J., \& Willoughby, A. R. (2002). The medial frontal cortex and the rapid processing of monetary gains and losses. Science, 295(5563), 2279-2282. http://dx. doi.org/10.1126/science.1066893

Gentsch, K., Grandjean, D., \& Scherer, K. R. (2013). Temporal dynamics of event-related potentials related to goal conduciveness and power appraisals. Psychophysiology, 50(10), 1010-1022. https://doi.org/10.1111/psyp.12079

Gentsch, A., Ullsperger, P., \& Ullsperger, M. (2009). Dissociable medial frontal negativities from a common monitoring system for self- and externally caused failure of goal achievement. Neuroimage, 47, 2023-2030. https://doi.org/10.1016/j.neuroimage.2009.05.064

Gratton, G., Coles, M. G., \& Donchin, E. (1983). A new method for off-line removal of ocular artifact. Electroencephalography and Clinical Neurophysiology, 55, 468-484. https://doi.org/10.1016/0013-4694(83)90135-9.

Gu, R., Feng, X., Broster, L. S., Yuan, L., Xu, P., \& Luo, Y. J. (2017). Valence and magnitude ambiguity in feedback processing. Brain and Behavior, 7(5), 1-12. https://doi.org/10.1002/brb3.672 
Gu, R., Lei, Z., Broster, L., Wu, T., Jiang, Y., \& Luo, Y. jia. (2011). Beyond valence and magnitude: A flexible evaluative coding system in the brain. Neuropsychologia, 49(14), 3891-3897. https://doi.org/10.1016/j.neuropsychologia.2011.10.006

Guay, F., Ratelle, C. F., \& Chanel, J. (2008). Optimal learning in optimal contexts: The role of self-determination in education. Canadian Psychology, 49, 233-240. http://dx.doi.org/10.1037/a0012758

Hajcak, G., Moser, J. S., Holroyd, C. B., \& Simons, R. F. (2007). It's worse than you thought: The feedback negativity and violations of reward prediction in gambling tasks. Psychophysiology, 44(6), 905-912. https://doi.org/10.1111/j.1469-8986.2007.00567.x

Hajihosseini, A., \& Holroyd, C. B. (2013). Frontal midline theta and N200 amplitude reflect complementary information about expectancy and outcome evaluation. Psychophysiology, 50(6), 550-562. https://doi.org/10.1111/psyp.12040

Hertwig, R., \& Engel, C. (2016). Homo Ignorans: Deliberately Choosing Not to Know. Perspectives on Psychological Science, 11(3), 359-372. https://doi.org/10.1177/1745691616635594

Hoefler, A., Athenstaedt, U., Corcoran, K., Ebner, F., \& Ischebeck, A. (2015). Coping with self-threat and the evaluation of self-related traits: An fMRI study. PLOS ONE, 10(9), 116. https://doi.org/10.1371/journal.pone.0136027

Holroyd, C., \& Coles, M. (2002). The neural basis of human error processing: Reinforcement learning, dopamine, and the error-related negativity. Psychological Review, 109(4), 679709. https://doi.org/10.1037//0033-295X.109.4.679

Holroyd, C. B., \& Yeung, N. (2012). Motivation of extended behaviors by anterior cingulate cortex. Trends in Cognitive Sciences, 16(2), 122-128. https://doi.org/10.1016/j.tics.2011.12.008

Huck, S., Szech, N., \& Wenner, L. M. (2015). More effort with less pay: On information avoidance, belief design and performance (Working Paper Series in Economics, Karlsruher Institut für Technologie (KIT), No. 72). Retrieved from http://econstor.eu/bitstream/10419/120879/1/836112962.pdf

Johnston, V. S., Miller, D. R., \& Burleson, M. H. (1986). Multiple P3s to emotional stimuli and their theoretical significance. Psychophysiology, 23, 684-694. http://dx.doi.org/ 10.1111/j.1469-8986.1986.tb00694.x

Kaufmann, T., Sütterlin, S., Schulz, S. M., \& Vögele, C. (2011). ARTiiFACT: a tool for heart rate artifact processing and heart rate variability analysis. Behavior Research Methods, 43(4), 1161-70. https://doi.org/10.3758/s13428-011-0107-7 
Keil, A., Bradley, M. M., Hauk, O., Rockstroh, B., Elbert, T., \& Lang, P. J. (2002). Largescale neural correlates of affective picture processing. Psychophysiology, 39(5), 641649. https://doi.org/10.1017.S0048577202394162, S0048577202394162

Keil, A., Debener, S., Gratton, G., Junghöfer, M., Kappenman, E. S., Luck, S. J., et al. (2014). Committee report: Publication guidelines and recommendations for studies using electroencephalography and magnetoencephalography. Psychophysiology, 51(1), 1-21. http://dx.doi.org/10.1111/psyp.12147

King, J. A., Korb, F. M., Cramon, D. Y. Von, \& Ullsperger, M. (2010). Post-error behavioral adjustments are facilitated by activation and suppression of task-relevant and taskirrelevant information processing. Journal of Neuroscience, 30(38), 12759-12769. https://doi.org/10.1523/JNEUROSCI.3274-10.2010

Koban, L., \& Pourtois, G. (2014). Brain systems underlying the affective and social monitoring of actions: An integrative review. Neuroscience and Biobehavioral Reviews, 46(P1), 71-84. https://doi.org/10.1016/j.neubiorev.2014.02.014

Koban, L., Pourtois, G., Bediou, B., \& Vuilleumier, P. (2012). Effects of social context and predictive relevance on action outcome monitoring. Cognitive, Affective, \& Behavioral Neuroscience, 12(3), 460-478. https://doi.org/10.3758/s13415-012-0091-0

Koban, L., Pourtois, G., Vocat, R., \& Vuilleumier, P. (2010). When your errors make me lose or win: event-related potentials to observed errors of cooperators and competitors. Social Neuroscience, 5(4), 360-374. https://doi.org/10.1080/17470911003651547

Koole, S. L.,\&Kuhl, J. (2003). In search of the real self: A functional perspective on optimal self-esteem and authenticity. Psychological Inquiry, 14, 43-48.

http://www.jstor.org/stable/1449039

Laborde, S., Mosley, E., \& Thayer, J. F. (2017). Heart rate variability and cardiac vagal tone in psychophysiological research - Recommendations for experiment planning, data analysis, and data reporting. Frontiers in Psychology, 8, 1-18.

https://doi.org/10.3389/fpsyg.2017.00213

Lane, R. D., McRae, K., Reiman, E. M., Chen, K., Ahern, G. L., \& Thayer, J. F. (2009). Neural correlates of heart rate variability during emotion. Neuroimage, 44(1), 213-222. http://dx.doi.org/10.1016/j.neuroimage.2008.07.056

Leary, M. R., Terry, M. L., Allen, A. B., \& Tate, E. B. (2009). The concept of ego threat in social and personality psychology: Is ego threat a viable scientific construct? Personality and Social Psychology Review, 13(3), 151-164. https://doi.org/10.1177/1088868309342595 
Legault, L., \& Inzlicht, M. (2013). Self-Determination, Self-Regulation, and the Brain: Autonomy Improves Performance by Enhancing Neuroaffective Responsiveness to SelfRegulation Failure. Journal of Personality and Social Psychology, 105(1), 123-138. https://doi.org/10.1037/a0030426

Liebowitz, M. R. (1987). Social phobia. Modern Problems of Pharmacopsychiatry, 22, 141173.

Love, J, Selker, R, Marsman, M, Jamil, T, Dropmann, D, Verhagen, AJ, \& Wagenmakers, EJ, JASP (Version 0.7) 2015 [Amsterdam free shareware https://jasp-stats.org].

Mansouri, F. A., Koechlin, E., Rosa, M. G. P., \& Buckley, M. J. (2017). Managing competing goals - A key role for the frontopolar cortex. Nature Reviews Neuroscience, 18(11), 645657. https://doi.org/10.1038/nrn.2017.111

McAuley, E., Duncan, T., \& Tammen, V. V. (1987). Psychometric properties of the Intrinsic Motivation Inventory in a competitive sport setting: A confirmatory factor analysis. Research Quarterly for Exercise and Sport, 60, 48-58. https://doi.org/10.1080/02701367.1989.10607413

Miller, D. T. (1976). Ego involvement and attributions for success and failure. Journal of Personality and Social Psychology, 34, 901-906. https://doi.org/10.1037/00223514.34.5.901

Miltner, W. H., Braun, C. H., \& Coles, M. G. (1997). Event-related brain potentials following incorrect feedback in a time-estimation task: Evidence for a generic neural system for error detection. Journal of Cognitive Neuroscience, 9, 788-798. http://dx. doi.org/10.1162/jocn.1997.9.6.788

Moller, A. C., Deci, E. L., \& Ryan, R. M. (2006). Choice and ego- depletion: The moderating role of autonomy. Personality and Social Psychology Bulletin, 32, 1024-1036. https://doi.org/10.1177/0146167206288008

Moors, A. (2007). Can cognitive methods be used to study the unique aspect of emotion: An appraisal theorist's answer. Cognition and Emotion, 21(6), 1238-1269. http://dx.doi. org/10.1080/02699930701438061

Nieuwenhuis, S., Aston-Jones, G., \& Cohen, J. D. (2005). Decision making, the P3, and the locus coeruleus-norepinephrine system. Psychological Bulletin, 131(4), 510-532. https://doi.org/10.1037/0033-2909.131.4.510

Nieuwenhuis, S., Holroyd, C. B., Mol, N., \& Coles, M. G. H. (2004). Reinforcement-related brain potentials from medial frontal cortex: Origins and functional significance. Neuroscience and Biobehavioral Reviews, 28(4), 441-448. http://dx.doi.org/10.1016/j. neubiorev.2004.05.003 
Nieuwenhuis, S., Richard Ridderinkhof, K., Blom, J., Band, G. P. H., \& Kok, A. (2001). Error-related brain potentials are differentially related to awareness of response errors: Evidence from an antisaccade task. Psychophysiology, 38(5), 752-760. https://doi.org/10.1017/S0048577201001111

Oliveira, F. T. P., McDonald, J. J., \& Goodman, D. (2007). Performance Monitoring in the Anterior Cingulate is Not All Error Related: Expectancy Deviation and the Representation of Action-Outcome Associations. Journal of Cognitive Neuroscience, 19(12), 1994-2004. https://doi.org/10.1162/jocn.2007.19.12.1994

Osinsky, R., Ulrich, N., Mussel, P., Feser, L., Gunawardena, A., \& Hewig, J. (2017). The feedback-related negativity reflects the combination of instantaneous and long-term values of decision outcomes. Journal of Cognitive Neuroscience, 29(3), 424-434. https://doi.org/10.1162/jocn_a_01055

Pfabigan, D. M., Alexopoulos, J., Bauer, H., \& Sailer, U. (2011). Manipulation of feedback expectancy and valence induces negative and positive reward prediction error signals manifest in event-related brain potentials. Psychophysiology, 48(5), 656-664. https://doi.org/10.1111/j.1469-8986.2010.01136.x

Pfabigan, D. M., Zeiler, M., Lamm, C., \& Sailer, U. (2014). Blocked versus randomized presentation modes differentially modulate feedback-related negativity and $\mathrm{P} 3 \mathrm{~b}$ amplitudes. Clinical Neurophysiology, 125(4), 715-726. https://doi.org/10.1016/j.clinph.2013.09.029

Plant, R. W., \& Ryan, R. M. (1985). Intrinsic motivation and the effects of selfconsciousness, self-awareness, and ego-involvement: An investigation of internallycontrolling styles. Journal of Personality, 53, 435-449. http://dx.doi.org/10.1111/j.14676494.1985.tb00375.x

Pyszczynski, T. O. M., \& Greenberg, J. (1983). Determinants of reduction in intended effort as a strategy for coping with anticipated failure. Journal of Research in Personality, 17(422), 412-422. https://doi.org/10.1016/0092-6566(83)90069-7

Polezzi, D., Sartori, G., Rumiati, R., Vidotto, G., \& Daum, I. (2010). Brain correlates of risky decision-making. Neuroimage, 49(2), 1886-1894. https://doi.org/10.1016/j.neuroimage.2009.08.068

Polich, J. (2007). Updating P300: An integrative theory of P3a and P3b. Clinical Neurophysiology, 118(10), 2128-2148. https://doi.org/10.1016/j.clinph.2007.04.019

Porges, S. W. (2001). The polyvagal theory: phylogenetic substrates of a social nervous system. International Journal of Psychophysiology, 42(2), 123-146. http://dx.doi.org/10.1016/s0167-8760(01)00162-3 
Porges, S. W. (2007). The polyvagal perspective. Biological Psychology, 74(2), 116-143. http://dx.doi.org/10.1016/j.biopsycho.2006.06.009

Pourtois, G. (2011). Early error detection predicted by reduced pre-response control process: An ERP topographic mapping study. Brain Topography, 23(4), 403-422. https://doi.org/10.1007/s10548-010-0159-5

Proudfit, G. H. (2015). The reward positivity: From basic research on reward to a biomarker for depression. Psychophysiology, 52(4), 449-459. https://doi.org/10.1111/psyp.12370

Raftery, A. E. (1995). Bayesian model selection in social research. In P. V. Marsden (Ed.), Sociological methodology 1995 (pp. 111-196). Cambridge, MA: Blackwell.

Rosenberg, M. (1965). Society and the adolescent self-image. Princeton, NJ: Princeton University Press.

Rosenberg, M., Schooler, C., Schoenbach, C., \& Rosenberg, F. (1995). Global self-esteem and specific self-esteem: Different concepts, different outcomes. American Sociological Review, 60, 141-156. http://dx.doi.org/10.2307/2096350

Ryan, R. M. (1982). Control and information in the intrapersonal sphere: An extension of cognitive evaluation theory. Journal of Personality and Social Psychology, 43, 450-461. http://dx.doi.org/10.1037/0022-3514.43.3.450

Ryan, R. M., \& Deci, E. L. (2000). Self-determination theory and the facilitation of intrinsic motivation, social development, and well-being. The American Psychologist, 55(1), 6878. https://doi.org/10.1037/0003-066X.55.1.68

Ryan, R. M., Connell, J. P., \& Plant, R. W. (1990). Emotions in non-directed text learning. Learning and Individual Differences, 2, 1-17. http://dx.doi.org/10.1016/10416080(90)90014-8

Ryan, R. M., Koestner, R., \& Deci, E. L. (1991). Ego-involved persistence: When freechoice behavior is not intrinsically motivated. Motivation and Emotion, 15, 185-205. https://doi.org/10.1007/BF00995170

Ryan, R. M., Mims, V., \& Koestner, R. (1983). Relation of reward contingency and interpersonal context to intrinsic motivation: A review and test using cognitive evaluation theory. Journal of Personality and Social Psychology, 45, 736-750. https://doi.org/10.1037/0022-3514.45.4.736

San Martin, R. (2012). Event-related potential studies of outcome processing and feed- backguided learning. Frontiers in Human Neuroscience, 6,1-17. http://dx.doi.org/10. 3389/fnhum.2012.00304 
Sedikides, C., \& Green, J. D. (2009). Memory as a self-protective mechanism. Social and Personality Psychology Compass, 3(6), 1055-1068. https://doi.org/10.1111/j.17519004.2009.00220.x

Sedikides, C., \& Green, J. D. (2004). What I don't recall can't hurt me: Information negativity versus information inconsistency as determinants of memorial self-defense. Social Cognition, 22(1), 4-29. https://doi.org/10.1521/soco.22.1.4.30987

Selimbegovic, L., Régner, I., Sanitioso, R. B., \& Huguet, P. (2011). Influence of general and specific autobiographical recall on subsequent behavior: The case of cognitive performance. Journal of Experimental Social Psychology, 47(1), 72-78. https://doi.org/10.1016/j.jesp.2010.08.011

Sedikides, C., \& Gregg. A. P. (2003). Portraits of the self. In M. A. Hogg \& J. Cooper (Eds.), Sage Handbook of Social Psychology (pp. 110-138). London: Sage Publications.

Sedikides, C., \& Koole, S. L. (2004). In defense of the self. Social Cognition, 22(1), 1-3. https://doi.org/10.1521/soco.22.1.1.30988

Severo, M. C., Walentowska, W., Moors, A., \& Pourtois, G. (2017). Goal impact influences the evaluative component of performance monitoring: Evidence from ERPs. Biological Psychology, 129. https://doi.org/10.1016/j.biopsycho.2017.08.052

Shen, L., Fishbach, A., \& Hsee, C. K. (2015). The motivating-uncertainty effect: Uncertainty increases resource investment in the process of reward pursuit. Journal of Consumer Research, 41, 1301-1315. https://doi.org/10.1086/679418

Sherman, D. K., \& Cohen, G. L. (2006). The Psychology of Self-defense: Self-Affirmation Theory. Advances in Experimental Social Psychology, 38(6), 183-242. https://doi.org/10.1016/S0065-2601(06)38004-5

Spencer, K. M., Dien, J., \& Donchin, E. (1999). A componential analysis of the ERP elicited by novel events using a dense electrode array. Psychophysiology, 36, 409-414. https://doi.org/10.1017/S0048577299981180

Spencer, K. M., Dien, J., \& Donchin, E. (2001). Spatiotemporal analysis of the late ERP responses to deviant stimuli. Psychophysiology, 38(2), 343-358. https://doi.org/10.1111/1469-8986.3820343

Stahl, J. (2010). Error detection and the use of internal and external error indicators: An investigation of the first-indicator hypothesis. International Journal of Psychophysiology, 77(1), 43-52. http://dx.doi.org/10.1016/j.ijpsycho.2010.04.005

Sutton, S., Braren, M., Zubin, J., \& John, E. R. (1965). Evoked-potential correlates of stimulus uncertainty. Science, 150, 1187-1188. http://dx.doi.org/10.1126/science. 150.3700 .1187 
Simon, J. R., \& Rudell, A. P. (1967). Auditory S-R compatibility: The effect of an irrele- vant cue on information processing. Journal of Applied Psychology, 51, 300-304. http://dx.doi.org/10.1037/h0020586

Simmons, J. P., Nelson, L. D., \& Simonsohn, U. (2011). False-positive psychology: Undisclosed flexibility in data collection and analysis allows presenting anything as significant. Psychological Science, 22(11), 1359-1366. https://doi.org/10.1177/0956797611417632

Task Force of the European Society of Cardiology and the North American Society of Pacing and Electrophysiology (1996). Heart rate variability: Standards of measure- ment, physiology interpretation, and clinical use. Circulation, 93, 1043-1065. http:// dx.doi.org/10.1161/01.CIR.93.5.1043

Thayer, J. F., Hansen, A. L., Saus-Rose, E., \& Johnsen, B. H. (2009). Heart rate variability, prefrontal neural function, and cognitive performance: The neurovisceral integration perspective on self-regulation, adaptation, and health. Annals of Behavioral Medicine, 37(2), 141-153. http://dx.doi.org/10.1007/s12160-009-9101-z

Toyomaki, A., \& Murohashi, H. (2005). The ERPs to feedback indicating monetary loss and gain on the game of modified "rock-paper-scissors." International Congress Series, 1278, 381-384. https://doi.org/10.1016/j.ics.2004.11.032

Ullsperger, M. (2017). Neural Bases of Performance Monitoring. In T. Egner (Ed.). The Wiley Handbook of Cognitive Control. Chichester, UK: John Wiley \& Sons, Ltd. https://doi.org/10.1002/9781118920497.ch17

Ullsperger, M., Danielmeier, C., \& Jocham, G. (2014a). Neurophysiology of performance monitoring and adaptive behavior. Physiological Reviews, 94(1), 35-79. http://dx.doi. org/10.1152/physrev.00041.2012

Ullsperger, M., Fischer, A. G., Nigbur, R., \& Endrass, T. (2014b). Neural mechanisms and temporal dynamics of performance monitoring. Trends in Cognitive Sciences, 18(5), 259-267. http://dx.doi.org/10.1016/j.tics.2014.02.009

Vansteenkiste, M., Simons, J., Lens, W., Sheldon, K. M., \& Deci, E. L. (2004). Motivating learning, performance, and persistence: The synergistic effects of intrinsic goal contents and autonomy-supportive contexts. Journal of Personality and Social Psychology, 87(2), 246-260. https://doi.org/10.1037/0022-3514.87.2.246

Van Vliet, I. M., \& Westenberg, H. G. M. (1999). Pharmacotherapy of social anxiety disorder. In H. G. M. Westenberg, \& J. A. Den Boer (Eds.). Focus on psychiatry: Social anxiety disorder (pp. 157-174). Amsterdam, The Netherlands: SynThesis Publishers. 
Vidal, F., Hasbroucq, T., Grapperon, J., \& Bonnet, M. (2000). Is the "error negativity" specific to errors? Biological Psychology, 51(2-3), 109-128.

https://doi.org/10.1016/S0301-0511(99)00032-0

Vocat, R., Pourtois, G., \& Vuilleumier, P. (2008). Unavoiable errors: A spatio-temporal analysis of time-course and neural sources of evoked potentials associated with error processing in a speeded task. Neuropsychologia, 46(10), 2545-2555.

https://doi.org/10.1016/j.neuropsychologia.2008.04.006

von Borries, A. K. L., Verkes, R. J., Bulten, B. H., Cools, R., \& de Bruijn, E. R. A. (2013). Feedback-related negativity codes outcome valence, but not outcome expectancy, during reversal learning. Cognitive, Affective, \& Behavioral Neuroscience, 13, 737-746. https://doi.org/10.3758/s13415- 013-0150-1

von Hippel, W., Lakin, J. L., \& Shakarchi, R. J. (2005). Individual differences in motivated social cognition: The case of self-serving information processing. Personality and Social Psychology Bulletin, 31(10), 1347-1357. https://doi.org/10.1177/0146167205274899

Walentowska, W., Moors, A., Paul, K., \& Pourtois, G. (2016). Goal relevance influences performance monitoring at the level of the FRN and P3 components. Psychophysiology, 53(7), 1020-1033. https://doi.org/10.1111/psyp.12651

Walentowska, W., Paul, K., Severo, M. C., Moors, A., \& Pourtois, G. (2018). Relevance and uncertainty jointly influence reward anticipation at the level of the SPN ERP component. International Journal of Psychophysiology, 132, Part B, 287-297. https://doi.org/10.1016/j.ijpsycho.2017.11.005

Walsh, M. M., \& Anderson, J. R. (2012). Learning from experience: Event-related potential correlates of reward processing, neural adaptation, and behavioral choice. Neuroscience and Biobehavioral Reviews, 36(8), 1870-1884. https://doi.org/10.1016/j.neubiorev.2012.05.008

Wentura, D., \& Greve, W. (2004). Who wants to be... erudite? Everyone! Evidence for automatic adaptation of trait definitions. Social Cognition, 22(1), 30-53. https://doi.org/10.1521/soco.22.1.30.30981

Wu, Y., \& Zhou, X. (2009). The P300 and reward valence, magnitude, and expectancy in outcome evaluation. Brain Research, 1286, 114-122. https://doi.org/10.1016/j.brainres.2009.06.032

Yeung, N., \& Sanfey, A. G. (2004). Independent coding of reward magnitude and valence in the human brain. Journal of Neuroscience, 24(28), 6258-6264. https://doi.org/10.1523/JNEUROSCI.4537-03.2004 
Zhou, Z., Yu, R., \& Zhou, X. (2010). To do or not to do? Action enlarges the FRN and P300 effects in outcome evaluation. Neuropsychologia, 48(12), 3606-3613.

https://doi.org/10.1016/j.neuropsychologia.2010.08.010 


\section{Supplementary Materials}

\section{Correlation between effort expenditure (Item 1 of IMI) and FRN}

Using a regression analysis, we assessed whether at the group level ( $n=68)$, the FRN reduction reported in the study might be more pronounced for individuals who reported lower effort expenditure (based on item 1 of the IMI). To this aim, we ran a linear regression for all participants together in RStudio (RStudio Team, 2015), using the FRN amplitude (collapsing positive and negative feedback) recorded at FCz electrode as dependent variable and the ratings for IMI item 1 (collapsing pre- and post-measures) as predictor (see Figure 1). This analysis failed to reveal a significant relationship between these two variables however, $F_{(1,66)}=2.251$, $p=0.1383$, with an $R^{2}=0.0330$, even though the results showed the expected pattern (i.e., less negative FRN for subjects reporting lower effort expenditure).

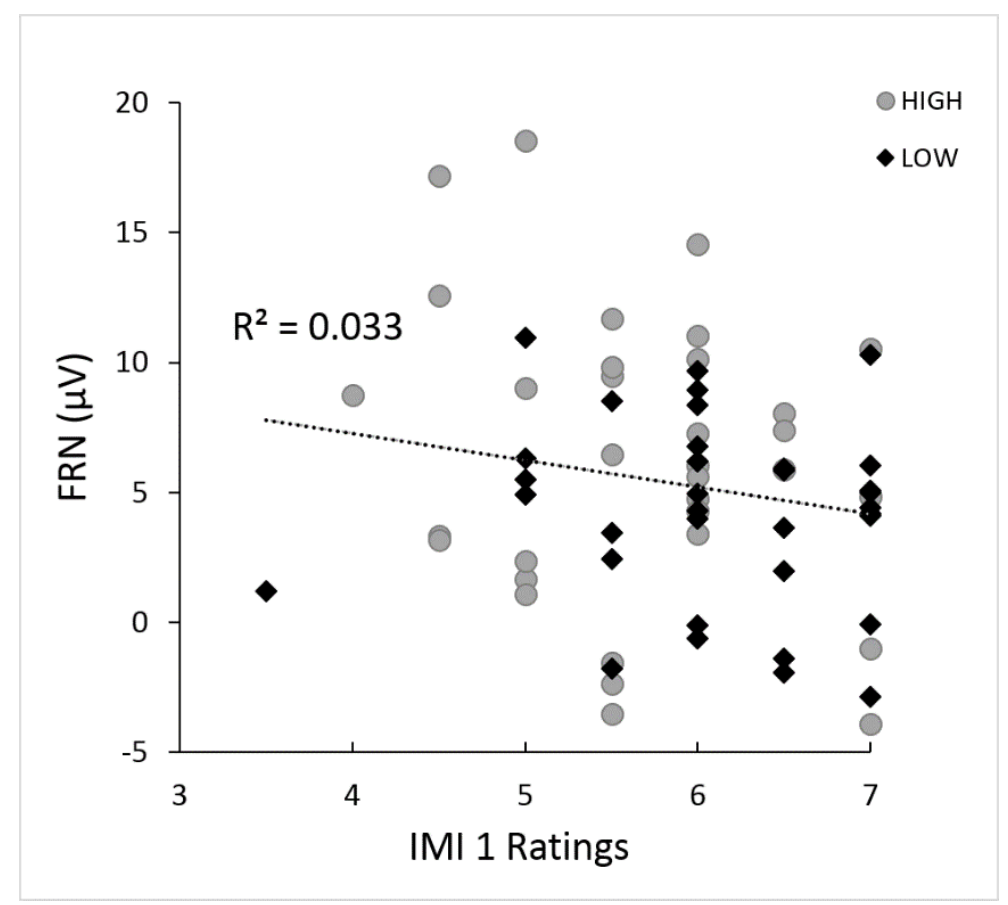

Supplementary Figure 1. Correlation between effort expenditure (Item 1 of IMI) and FRN. We failed to observe at the group level $(n=68)$ a significant relationship between these two variables. 


\section{Peak-to-peak analysis of FRN}

An alternative scoring method (i.e., a peak-to-peak analysis) was also performed to quantify FRN (see Ferdinand et al., 2012; Mushtaq et al., 2016; Oliveira et al., 2007), by extracting this ERP component relative to its preceding peak (i.e., P2 component). We identified the mean voltage of the P2 component within 180-230 ms and of the FRN within 250-300 ms over the FCz channel. Then, the value of the former was subtracted from the latter for each subject and condition separately. An ANOVA run on these values, which included the between-subjects factor of VALENCE (i.e., negative vs. positive feedback) and the withinsubject factor of IMPACT (i.e., high vs. low), revealed a significant main effect of VALENCE, $\mathrm{F}_{(1,66)}=30.223, \mathrm{p}<0.001, \eta_{\mathrm{p}}{ }^{2}=0.314$. This effect translated a larger $\mathrm{FRN}$ for negative $(\mathrm{M}=-$ $6.42 \mu \mathrm{V}, \mathrm{SEM}=0.52)$ than for positive feedback $(\mathrm{M}=-4.31 \mu \mathrm{V}, \mathrm{SEM}=0.50)$. The main effect of IMPACT, $\mathrm{F}_{(1,66)}=0.217, \mathrm{p}=0.643, \eta_{\mathrm{p}}{ }^{2}=0.003$, as well as the VALENCE $\mathrm{x}$ IMPACT interaction, $\mathrm{F}_{(1,66)}=0.935, \mathrm{p}=0.337, \eta_{\mathrm{p}}^{2}=0.014$, were both not significant.

\section{Response-locked ERP data (ERN/CRN)}

Unlike feedback-locked data, goal impact did not influence response-locked ERP data at the ERN or CRN level (see main text for values and statistical analysis). This dissociation was already found in our previous study (Severo et al., 2017). As reported in the main text, the ERN (i.e. response errors, corresponding here to false alarms on the no-go stimulus) was significantly larger than the CRN (i.e., hits, corresponding here to correct key presses on the go stimulus), as expected (see Figure 2). 
A)

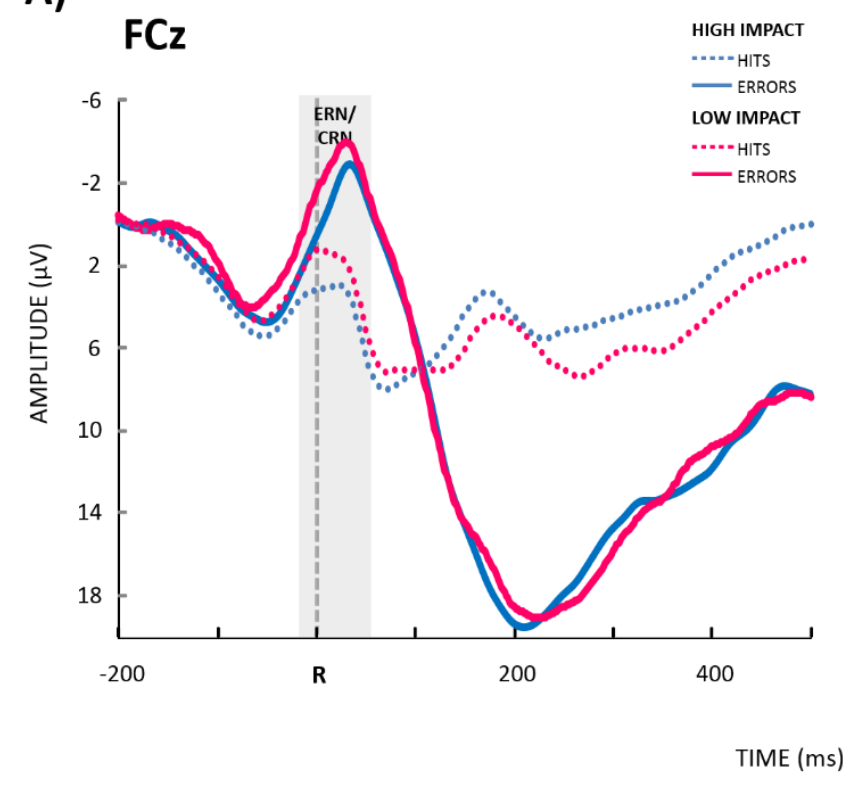

B)

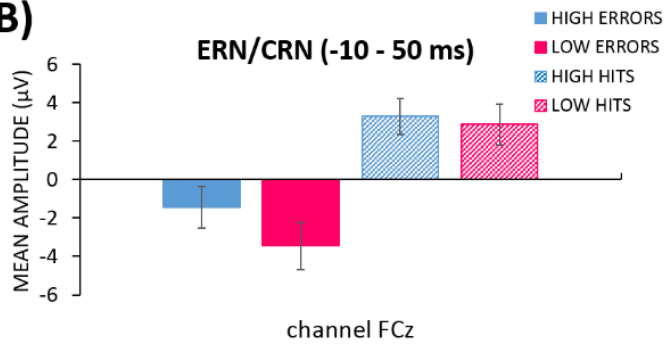

C)

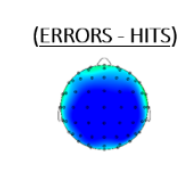

(LOW-HIGH)
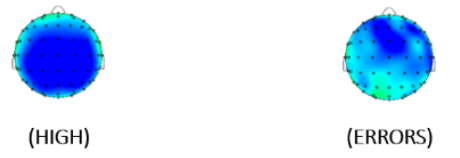

(ERRORS)

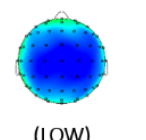

(LOW)

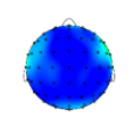

(HITS)

Supplementary Figure 2. Response-locked ERP results. (A): Grand average ERP waveforms for channel FCz, separately for each response type and impact group. A conspicuous ERN component was observed following response errors (solid lines), yet without modulation by goal impact. The same conclusion held for the CRN elicited by hits (dashed lines). Note that $\mathrm{R}$ stands for response onset and negativity is plotted upwards. (B) Bar graphs representing mean amplitudes ( $\pm 1 \mathrm{SEM}$ ) for the ERN/CRN component extracted in a -10 to $50 \mathrm{~ms}$ time window. (C) The corresponding topographical scalp maps for the ERN/CRN.

\section{References:}

Mushtaq, F., Wilkie, R. M., Mon-Williams, M. A., \& Schaefer, A. (2016). Randomised prior feedback modulates neural signals of outcome monitoring. Neuroimage, 125, 868-879. http://dx.doi.org/10.1016/j.neuroimage.2015.10.046.

Oliveira, F. T. P., McDonald, J. J., \& Goodman, D. (2007). Performance Monitoring in the Anterior Cingulate is Not All Error Related: Expectancy Deviation and the Representation of Action-Outcome Associations. Journal of Cognitive Neuroscience, 19(12), 1994-2004. https://doi.org/10.1162/jocn.2007.19.12.1994

Ferdinand, N. K., Mecklinger, A., Kray, J., \& Gehring, W. J. (2012). The processing of unexpected positive response outcomes in the mediofrontal cortex. The Journal of Neuroscience, 32(35), 12087-12092. https://doi.org/10.1523/JNEUROSCI.1410-12.2012

Severo, M. C., Walentowska, W., Moors, A., \& Pourtois, G. (2017). Goal impact influences the evaluative component of performance monitoring: Evidence from ERPs. Biological Psychology, 129. https://doi.org/10.1016/j.biopsycho.2017.08.052 